This item was submitted to Loughborough's Research Repository by the author.

Items in Figshare are protected by copyright, with all rights reserved, unless otherwise indicated.

\title{
A through-life costing methodology for use in product-service-systems
}

\section{PLEASE CITE THE PUBLISHED VERSION}

http://dx.doi.org/10.1016/j.jpe.2014.02.016

\section{PUBLISHER}

(c) Elsevier

\section{VERSION}

AM (Accepted Manuscript)

\section{PUBLISHER STATEMENT}

This work is made available according to the conditions of the Creative Commons Attribution-NonCommercialNoDerivatives 4.0 International (CC BY-NC-ND 4.0) licence. Full details of this licence are available at: https://creativecommons.org/licenses/by-nc-nd/4.0/

\section{LICENCE}

CC BY-NC-ND 4.0

\section{REPOSITORY RECORD}

Newnes, Linda B., Nils E. Thenent, Glenn Parry, and Yee M. Goh. 2019. "A Through-life Costing Methodology for Use in Product-service-systems". figshare. https://hdl.handle.net/2134/17067. 
Elsevier Editorial System(tm) for International Journal of Production Economics Manuscript Draft

Manuscript Number: IJPE-D-12-00617R3

Title: A Through-Life Costing Methodology for Use in Product-Service-Systems

Article Type: Research Paper

Keywords: Through-life costing; product-service systems; cost estimation; availability contracting; defence and aerospace.

Corresponding Author: Dr Ettore Settanni,

Corresponding Author's Institution: University of Bath

First Author: Ettore Settanni

Order of Authors: Ettore Settanni; Linda B Newnes; Nils E Thenent; Glenn Parry; Yee M Goh

Abstract: Availability-based contracts which provide customers with the use of assets such as machines, ships, aircraft platforms or subsystems like engines and avionics are increasingly offered as an alternative to the purchase of an asset and separate support contracts. The cost of servicing a durable product can be addressed by Through-life Costing (TLC). Providers of advanced services are now concerned with the cost of delivering outcomes that meet customer requirements using combinations of assets and activities via a Product Service System (PSS). This paper addresses the question: To what extent are the current approaches to TLC methodologically appropriate for costing the provision of advanced services, particularly availability, through a PSS? A novel methodology for TLC is outlined addressing the challenges of PSS cost assessment with regard to 'what?' (cost object), 'why/to what extent?' (scope and boundaries), and 'how?' (computations). The research provides clarity for those seeking to cost availability in a performance-orientated contractual setting and provides insight to the measures that may be associated with it. In particular, a reductionist approach that focuses on one cost object at a time is not appropriate for a PSS. Costing an advanced service delivered through a PSS is a problem of attributing the value of means to the economic activities carried out for specific ends to be achieved. Cost results from the interplay between monetary and nonmonetary metrics, and uncertainties thereof. Whilst seeking to ensure generality of the findings, the application of TLC examined here is limited to a military aircraft platform and subsystems. 


\section{A Through-Life Costing Methodology for Use in Product-Service-Systems}

\section{Author Details}

Author 1 Corresponding Author

Ettore Settanni

Department of Mechanical Engineering, University of Bath

Claverton Down, Bath, BA2 7AY

United Kingdom

e-mail: E.Settanni@bath.ac.uk

Tel: $+44(0) 1225385937$

Mobile: $+44(0) 7413846776$

Author 2

Linda B. Newnes

Department of Mechanical Engineering, University of Bath

Claverton Down, Bath, BA2 7AY

United Kingdom

Tel: +44 (0) 1225386291

Author 3

Nils E. Thenent

Department of Mechanical Engineering, University of Bath

Claverton Down, Bath, BA2 7AY

United Kingdom

Tel: $+44(0) 1225385937$

\section{Author 4}

Glenn Parry

Faculty of Business \& Law, UWE Frenchay Campus

Coldharbour Lane, Bristol, BS16 1QY

United Kindgom

Tel: $+44(0) 1173283453$

\section{Author 5}

Yee Mey Goh

Wolfson School of Mechanical and Manufacturing Engineering, Loughborough University

Epinal Way, Loughborough, LE11 3TU

United Kingdom

Tel: $+44(0) 1509227672$

\section{Acknowledgments}

The authors gratefully acknowledge the support provided by the Department of Mechanical Engineering at the University of Bath, the Innovative electronics Manufacturing Research Centre (leMRC) and the Engineering and Physical Sciences Research Council (EPSRC) for funding the research. The authors wish to thank three industrial partners, and two anonymous reviewers for their helpful and constructive comments. 

for Use in Product-Service-Systems

Article Classification: Research paper

\begin{abstract}
Availability-based contracts which provide customers with the use of assets such as machines, ships, aircraft platforms or subsystems like engines and avionics are increasingly offered as an alternative to the purchase of an asset and separate support contracts. The cost of servicing a durable product can be addressed by Through-life Costing (TLC). Providers of advanced services are now concerned with the cost of delivering outcomes that meet customer requirements using combinations of assets and activities via a Product Service System (PSS). This paper addresses the question: To what extent are the current approaches to TLC methodologically appropriate for costing the provision of advanced services, particularly availability, through a PSS? A novel methodology for TLC is outlined addressing the challenges of PSS cost assessment with regard to 'what?' (cost object), 'why/to what extent?' (scope and boundaries), and 'how?' (computations). The research provides clarity for those seeking to cost availability in a performance-orientated contractual setting and provides insight to the measures that may be associated with it. In particular, a reductionist approach that focuses on one cost object at a time is not appropriate for a PSS. Costing an advanced service delivered through a PSS is a problem of attributing the value of means to the economic activities carried out for specific ends to be achieved. Cost results from the interplay between monetary and non-monetary metrics, and uncertainties thereof. Whilst seeking to ensure generality of the findings, the application of TLC examined here is limited to a military aircraft platform and subsystems.
\end{abstract}

\title{
Keywords:
}

Through-life costing; product-service systems; cost estimation; availability contracting; defence and aerospace. 


\section{Introduction}

Through-Life Costing (TLC) has its roots in defence procurement practices and has been extensively applied across several fields (Korpi and Ala-Risku, 2008). Typically, TLC begins with the identification of a long-life asset such as a building, an aircraft, a piece of equipment, or one of their constituent parts. With the asset acting as the centre point, a one-off appraisal of the disbursements associated with its acquisition and existence over a time span is carried out (Dhillon, 2010). TLC often involves the designer forecasting how much alternative product concepts should cost as a direct consequence of their features, focussing upon those related to inherent reliability (Newnes et al., 2008). A common assumption in TLC is that the distinction between the Original Equipment Manufacturer (OEM) and its customer's responsibilities for product acquisition and ownership is clear-cut and therefore so are the cost items of concern (Chen and Keys, 2009). Such a logic reflects a business context in which the OEM's responsibility is to design and manufacture a product, whilst equipment failure in the use phase provides an additional revenue stream for the OEM after sales and support service. The 'product and support' business model incentivises a 'throw it over the wall' approach with respect to the customer, and is detrimental to product reliability (Caldwell and Settle, 2011).

There have been attempts to challenge the established business model described. With reference to military equipment, it has long been noted that allowing the purchaser's viewpoint to be represented only when contractual reliability requirements are specified does not ensure a satisfactory final deliverable per se (Perrigo and Easterday, 1974). Integrated Logistic Support (ILS) emphasizes the ability of a weapon system to deliver the output for which it is designed (Galloway, 1996). Long-term service agreements incentivise the usability of an asset while covering all or most of the costs associated with support activities (BS EN IEC, 2009). In particular, availability-based contracts aim to guarantee that an asset performs its function when called upon to do so, and typically uses the ratio between satisfactory operations to downtime as a metric (Jazouli and Sandborn, 2011). Availability-based contracts are increasingly used by engineering OEMs. For example, Rolls-Royce Plc.'s move from selling aircraft engines to selling the availability of its engines has been has been acknowledged as a success story that "...could offer lessons for Britain's other industries" (The Economist, 2011). Similar agreements are also re-shaping the approach to procuring industrial machinery (Hypko et al., 2010), and the development of infrastructure projects through Public-Private Partnerships (Sharma and Cui, 2012). 
An advanced service sustains the customers' core business processes and the service delivery the offering itself (Ng et al., 2011; Baines and Lightfoot, 2013). This construct is a knowledgeintensive socio-technical system referred to as Product-Service-System - PSS (Meier et al., 2010).

An OEM transforming to a service provider is concerned with the cost of delivering a result through a PSS (Tukker and Tischner, 2006), for example agreed availability or other performance levels over time. TLC often includes complementary non-monetary performance metrics such as the availability of an item. Ntuen and Moore (1986) provide an early overview of this approach to TLC. However, attention is placed on a stand-alone product unit and its reliability features which it is assumed, once designed-in, will hold indefinitely. How a product instance operates, fails and is restored to operation is typically described by means of time distributions. Essentially, for modelling purposes the product unit is stripped of its broader delivery, use and support context. Neely (2005) illustrates that performance is attained through a business's actions, their effectiveness (the extent to which customer requirements are met) and efficiency (how economically the resources are utilised). From this perspective the cost of performance is not designed into a product, rather, it is the cost of doing something 'right' from the customer's point of view (e.g. delivering value 'in use' through an outcome - see Ng et al., 2011), or dealing with the consequences of failing to do so. As such, cost is contained in the flow of work through the organisational system (Seddon et al., 2011).

The academic literature dealing with advanced services, in particular availability, provided via a PSS focuses exclusively on the cost of the in-service stage of an individual durable product, without questioning and enriching substantially the overall methodology of TLC. For example, Lindahl et al. (2014) compare integrated product-service offerings and more traditional product offerings without specifying what is meant by TLC, or disclosing how it is performed. Datta et al. (2010) provide extensive discussion and a framework, but suggest combinations of existing cost estimation techniques for use at a particular product-accompanying service lifecycle stage. Huang et al. (2012) analyse these techniques and identify the challenges of adapting them for the purpose of service cost estimation. In both cases TLC is not presented as an autonomous methodology but is the result of the application of different cost estimating techniques. The distinction between methodology and technique is relevant. Methodology is concerned with 'thinking about how to think', guiding the intellectual process of choosing concepts and deciding how they might be structured, whilst techniques are well-defined ways of 'going about' a problem: like cookbooks, if followed will produce a defined outcome (Wilson, 2001). 
The purpose of the research presented in this paper is twofold: first to ascertain whether and to

what extent the TLC literature provides sufficient methodological foundation in the case of costing an advanced service delivered by a PSS, particularly availability; and second to outline a methodology for TLC, addressing the challenges of PSS cost assessment related to the 'what?' (cost object), 'why/to what extent?' (scope and boundaries), and 'how?' (computations and metrics).

The remainder of this paper is structured as follows. Section 2 presents the research questions and strategy. Sections 3 summarises the state-of-the-art in TLC. Section 4 identifies the challenges of costing advanced services provided through a PSS, and analyses the TLC literature accordingly. In section 5 the findings are discussed and a methodology of TLC outlined. Section 6 summarises the contribution and limitations of this research and links to future work.

\section{Research questions and strategy}

This paper answers the following research questions:

RQ1: To what extent are the concepts and structures embedded in the prevailing approaches to through-life costing appropriate for costing advanced services provided via a product-service-system?

RQ2: What methodological aspects of through-life costing should be reconsidered for use in product-service-systems?

The research strategy followed to address the research questions is shown in Figure 1, and can be summarised in two main steps:

(1) Provide analysis and synthesis of an extended body of literature on TLC at the interface between key fields - management, design and engineering. Both narrative (tables) and metasynthesis are used to enable comparison between strands of literature which are heterogeneous in terms of methodologies and concepts (Tranfield et al., 2003).

(2) Build on the identified aspects of providing advanced service through a PSS which are a challenge for TLC to set guidelines which stimulate the intellectual process of analysis (Wilson, 2001), and provide directions for future research (Webster and Watson, 2002).

\section{INSERT Figure 1 HERE}

Figure 2 gives an overview of the composition of the 128 works on TLC reviewed in the first step. The contributions were retained based on the insight they provide into TLC methodology in terms of concepts (theory and frameworks), models (computational structures and metrics) and state-of-thePage 3 
art (survey and review). Works on TLC within environmental management have been largely excluded due to their specific methodological issues (Settanni, 2008). Finally, applications in which TLC is merely mentioned e.g., to make generic claims on savings associated with particular product designs, were not included.

\section{INSERT Figure 2 (A, B) HERE}

References have been accessed via keyword searches of librarian services (IEEE Xplore, EBSCO), management and engineering publishers' databases and web-based resources (NATO Research and Technology Organisation, RAND Corporation, and the Management and Accounting Web). The literature features a heterogeneous terminology - the approach being labelled alternatively as e.g., Life Cycle Costing (LCC), Whole-life Costing (WLC), Total Cost of Ownership (TCO). Hence, the search was initiated with the keywords "life" and "cost", and then refined using "availability" or "performance". Whilst no date restrictions have been applied it was noted that the literature on TLC up to the early 1980s was comprehensively covered by Gupta and Chow (1985) who examined over 600 works. Each reference is considered as a potential source, which facilitates the identification of the earliest works.

In order to provide focus in terms of case studies reviewed, preference has been accorded to applications of TLC in defence and aerospace - be it whole military aircraft platforms or their subsystems, aero-engines and avionics. This choice takes into account that a range of other applications have been reviewed already (Korpi and Ala-Risku, 2008). In addition there is empirical evidence that availability and performance-based contracts are becoming more frequently employed in the chosen sector. For example, the UK Ministry of Defence (MoD), is seeking a substantial move away from traditional support arrangements with industry by means of wholeaircraft availability contracts (Elford, 2011). However, the choice of applications reviewed serves as a lens to focus, and the generality of this research's findings is not restricted to these applications.

\section{State-of-the-art}

State-of-the-art in TLC includes 27 works, either investigating the extent to which it has been implemented in specific sectors or geographic areas (Table 1), or literature reviews (Table 2).

INSERT Table 1 HERE

INSERT Table 2 HERE 
TLC is still perceived by industry as an unfamiliar, poorly understood, infrequently implemented

\section{Literature exploration and analysis}

Work on TLC other than state-of-the-art research consists of 101 publications, including conceptual $(26.7 \%)$ and quantitative works $(73.3 \%)$. Only $17.8 \%$ of the reviewed references refer explicitly to a business model based on availability or performance-based contracting.

The exploration and analysis of current research on TLC is structured around the challenges the concept of PSS may pose to the 'what?' (cost object), 'why/to what extent?' (scope and boundaries), and 'how?' (computations and metrics) of TLC, as shown in Figure 3.

\section{INSERT Figure 3 HERE}

Each of these aspects is discussed in separate subsections. The reviewed publications have been individually summarised in the Appendix using tables (Table A.1 to Table A.6). 


\subsection{Cost objects (What?)}

Challenge 1: What is the appropriate cost object when costing an advanced service delivered by a PSS?

A cost object is "...any item, such as products, customers, departments, projects, activities and so on, for which costs are measured and assigned" (Hansen and Mowen, 2003). From this definition, the unit of analysis for assessing cost can equally be:

- A process, that is, an entity delivering a range of products or services (e.g., an assembly line, a flight operation or mission); or

- A stand-alone instance of product or service exhibiting certain characteristics (e.g., an assembled fighter jet, a target struck), or even an instance of time (e.g., a fiscal year);

A process can be described as a structured collection of interrelated purposeful actions, or operations, aimed to produce a result of value to internal or external customers. It does so by engaging the services of means (inputs) to achieve ends (outputs) under certain operating conditions and over a time interval. Figure 4 (a) shows this process structure, and how it replicates at different levels of aggregation. A process' input is referred to as resource to denote a capability acquired from outside the process' boundaries to pursue a course of action (Hansen and Mowen, 2003). A process' output is referred to as outcome to denote some final level of accomplishment resulting from an endeavour (Doost, 1996). Heijungs (2001) provides an extensive discussion, and Aguilar-Saven (2004) an overview of process representation techniques. Figure 4(b) shows cost categories associated directly and exclusively with a standalone instance, without indication of how the means involved result in intermediate and final ends. This indication is missing also in Figure 4(c) where cost categories and output volumes are aggregated over an instance of time.

INSERT Figure 4 (A, B, C) HERE

Placing focus on 'inputs', 'outputs' or 'outcomes' determines what the relevant cost information is. For illustrative purposes, consider the tactical unmanned air vehicle (UAV) program described by Hoyle (2013). Focusing on the program's inputs emphasises the amount of money expected to be spent on equipment and support over the next financial years (say, f160m). However, annual expenditures only express the acquisition of a 'potential' capability to pursue a particular course of action, not what is achieved by that spending (Anagboso and Spence, 2009). Focusing on the program's outputs emphasises the result of the acquisition process (e.g. 54 UAVs procured at f0.34m each). An UAV acquired only represents the means to achieve an end. Analysis of the service 
outcome (e.g., to deliver target acquisition and reconnaissance services) reveals that the release-toservice procedure for the UAV is still pending, and that an interim arrangement (worth $f 61.3 \mathrm{~m}$ ) was needed to provide capability via the lease of a different type of UAV.

These alternative views on cost objects substantiate the first challenge.

Product, service, process and system are intertwined concepts. Sampson (2012) highlights that service is better defined with reference to the work of a process, than by subtracting features from the concept of a product. Batista et al. (2008) suggest that the general principles and characteristics of systems can be applied to the understanding and management of service processes. Thenent et al. (2012) discuss technological knowledge, or detailed process understanding, as the foundation to capture the interplay rather than exacerbate the differences between services and the physical artefacts involved in a PSS. Finally, in the field of design, the technical representation of the PSS usually contains indications about the potential functions delivered by the technical system, the interaction between different actors, functionalities and the flows of events (Kim et al., 2011). A PSS cannot be identified with a stand-alone product, service, or process. Rather, a PSS is a specific type of delivery system aiming to meet a service demand (Wang et al., 2013). This is summarised in the following proposition:

Proposition 1: A reductionist approach that focuses on one cost object at a time is not appropriate for a PSS. A PSS is a system potentially involving multiple, interconnected and interacting cost objects simultaneously.

Using this proposition and the cost objects identified previously and summarised in Figure 5, the literature on TLC was analysed. Figure 6 shows the results of this analysis.

\section{INSERT Figure 5 HERE}

\section{INSERT Figure 6 HERE}

In eight of the reviewed cases the reference unit of analysis was a delivery system (the enterprise), but none examines a PSS. Only two of them are not conceptual works, whilst the remainder are often in fields that are adjacent to TLC, such as Supply Chain Costing (Schulze et al., 2012). Even when activities are explicitly mentioned, for example to refer to the configuration of the maintenance logistics support organisation (Kiang, 1979) or to a company's value chain (Clinton and Graves, 1999) they serve as cost categories, rather than autonomous cost objects, structured through explicit logical relationships within the enterprise. 
The analysis confirms that TLC models deal with one cost object at a time and assume that all the relevant costs are directly related to that object (Emblemsvåg, 2003). In 92.1\% of the cases considered, objects were typically one or more of the following: a product unit; a design instance for a product platform or family; an instance of product-related service; an instance of time over which the actions of bringing forth, sustaining, or disposing of a product occur (sometimes addressed aggregately as 'genopersistation' - see Dean, 1993). Also, product and service instances are usually related through the features of a product, without otherwise interacting. This aspect of TLC modelling is illustrated in Figure 7 through an IDEFO diagram (NIST, 1993).

\section{INSERT Figure 7 HERE}

A service instance in TLC can be generalised as the result of either an utilisation or a sustaining event. In the utilisation case, a service is quantified in terms of a product fulfilling its intended function. For example, an utilisation occurrence may engage the services of a specific military aircraft expressed as a number of missions, sorties or flight hours per aircraft (Roskam, 1990). A service rendered by a sustaining event is typically expressed through a one-to-one correspondence with a failure, that is, the inability of an asset utilisation occurrence to render its service - see, for example, Sandborn (2013). The cost of a support service instance is then typically multiplied by the frequency of occurrence of the service over a time-span. An instance of service is a cost object in $17.8 \%$ of cases, none of which deals with utilization events. Three of these references identify a PSS with an instance of support service. Expenditures related to utilisation events are typically considered aggregately over a product life-span, and then 'normalised' by the amount of service output (e.g., flying hours) recorded over the same period (Hitt, 1997). In this situation, corresponding to that depicted in Figure $4(\mathrm{c})$, the service output serves as an allocation base rather than as a cost object.

An instance of time is a cost object in most cases (88\%), and the only object in circa $50 \%$ of cases. Typically, this occurs for investment appraisals where the common assumption is that the monetary value of individual products and services is known and can be associated directly with a time-span. This also occurs in half of the reviewed works concerned with availability-based contracts. For example, Feldman et al. (2009) focus on the time interval over which a socket (an installation location for an avionic Line Replaceable Unit - LRU) is subject to a certain support regime, whilst the cost of individual LRUs, sockets, or maintenance interventions is given. 
Finding 1: TLC deals with one cost object at a time, be it an instance of product, service or

\subsection{Viewpoint (Why/to what extent?) \\ Challenge 2: What is the purpose of costing an advanced service delivered by a PSS? What are the scope and boundaries of the analysis?}

A cost object's cost is calculated for a purpose and is set within a scope. The combination of scope and purpose defines the viewpoint adopted in calculating that cost.

Commonly, the purpose of TLC is stated in terms of its intended application: e.g., to support affordability studies, source selection studies, design trade-offs etc. (Asiedu and Gu, 1998). In the light of recent critiques (Keller et al., 2014), the purpose should be investigated in terms of whether insight is needed to provide a number that will get a 'one-off' approval, e.g. for budgeting purposes, or for controlling cost on a continuous basis rather than futile attempts to predict it 'right first time'.

The latter purpose underpins a more strategic management of costs. Insight is required to create or sustain a competitive advantage within a specific industrial setting by looking both 'inward' and 'outward' to an organisation's suppliers, customers and competitors. The advantage sought tends to relate to efficient resource usage, increased value delivered to the customer and strategic positioning in the marketplace through exploitation of the activities contributing to customer value realisation (Cinquini and Tenucci, 2010). The scope of the analysis is framed in terms of activities undertaken both within the individual firm's value chain and with suppliers upstream and customers downstream (Hansen and Mowen, 2003).

Another purpose is should-cost estimating, that is the generation of a one-time cost estimate independent of specific organisational and industrial settings. It applies when the relationship sought with other actors is of an arm's length type as opposed to a strategic alliance (Ellram, 1996). A typical example is an organisation assessing the fairness of the price a supplier charges by independently calculating a product's should-cost. Another example is the comparison of competing product designs, where a cost estimate has to be generated in the absence of a profound understanding of the product, the methods of manufacture/processes and relationships between processes (Roy, 2003). In this case, knowing cost in absolute terms may not be the main aim, rather, relative accuracy is sought (Sandborn, 2013). The scope of a should-cost estimate may extend 
beyond the time a product is purchased by a customer, without reliance on insights into value creating activities within and beyond the four walls of the organisation.

Hence, a second challenge concerns the diversity of purpose and scope in calculating a cost object's cost.

Underlying a PSS is typically an intent to benefit from long-term strategic alliances. An advanced service provider is concerned with monitoring and managing interlinked activities spanning across organisations which continuously meet contracted levels of performance. Upstream, there is a need to align and interact with the supply network. Downstream, the ability to achieve contracted results is subject to the contribution of resources and activities by the customer and the provider, making the boundaries between them more fluid (Ng et al., 2011). The purpose of a PSS may be shared by a diverse network of stakeholders undertaking a complex offset of interdependent activities within the virtual boundaries defined by the concept of enterprise (Purchase et al., 2011). Identifying the service-delivering activities and their linkages is necessary in order to adequately address service uncertainty (Erkoyuncu et al., 2011b).

Proposition 2: If the purpose of a PSS is to exploit strategic alliances on a continuous basis its scope should cover interlinked activities performed within and across the organisational boundaries. Its scope should be also inter-temporal, since the impact of decisions on the state of the PSS at subsequent times has to be considered.

To address this proposition and the purposes and scopes previously identified, the literature on TLC has been analysed according to the dimensions shown in Figure 8.

\section{INSERT Figure 8 HERE}

Table 3 shows different standpoints of "life-cycle" taken in the TLC literature when defining the scope of analysis. A life cycle can be the time-span a product exists - be it the time a unit of product is with the customer; the overall duration of a provider's involvement over that product; or the time a product platform or family is sold in the market. Another view is that an engineering system progresses through its life-cycle through the actions, performed and managed within the organisations involved. These actions should be expressed in terms of their outcomes, relationships and occurrence (BS ISO/IEC, 2002). Aligning these standpoints is challenging, especially in the absence of explicit links between the activities performed at the enterprise level, which involve multiple products and services simultaneously, and an individual unit of product existing over time. 


\section{INSERT Table 3 HERE}

Figure 9 shows that TLC is mainly employed for should-cost estimation purposes (85\% of cases), which is physiological in a 'product and support' business model. Typically, the aim is to convince the customer of the superiority of one product design over another. This is achieved by showing that a purchasing behaviour that requires higher immediate disbursements will result in savings for the customer while owning, operating and maintaining the product over time. Typical examples include energy-efficient eco-innovations (Kaenzig and Wüstenhagen, 2010) and high-reliability assets like Prognostic Health Monitoring-equipped avionics (Jazouli and Sandborn, 2011). Those works addressing the need to identify and exploit internal and external linkages between activities within TLC are mostly conceptual (66.7\%). Also in terms of practical implementation, TLC is the least popular amongst strategic cost management tools the likes of value chain costing, target costing, and activity-based management (Cinquini and Tenucci, 2010).

\section{INSERT Figure 9 HERE}

Most of the works reviewed identify a life cycle with reference to one unit of product and the time-span such a unit is with the user (60.4\%). The producer and market viewpoints on life cycle feature, respectively, in $22.8 \%$ and $7 \%$ of works. From these viewpoints, a firm is concerned with a product as a platform rather than as a unit. A market viewpoint typically links to a products' sale volumes, and it has been used also to address the cost ramifications of obsolescence for an electronic product unit (Prabhakar and Sandborn, 2012). Finally, a scope defined in terms of interlinked activities (15\% of cases) is less frequently associated with the concept of TLC than it is with adjacent strategic cost management approaches, namely Supply Chain Costing (SCC) and InterOrganisational Cost Management (IOCM) - see Seuring and Goldbach (2002). Circa 5\% of works conceptually combine time and value-chain based life cycle concepts to show that activities grouped under different life cycle stages are carried out concurrently at different times within the enterprise, as in Clinton and Graves (1999).

Finding 2 TLC is a one-off, should-cost estimation exercise undertaken by the buying or the selling organisation independently. Its scope tends to be determined as the time-span a product unit exists, rather than the actions performed within the enterprise, their outcomes, relationships and occurrence. 


\subsection{Computations (How?)}

Challenge 3: What are the computational aspects of costing an advanced service delivered through a PSS? What are the metrics involved?

From a computational viewpoint, cost assessments differ in terms of cost modelling rationale, underlying concept of cost and use of non-monetary metrics.

The cost modelling rationale determines how the link between a cost object and its cost is established. Building on previous work (Curran et al., 2004) the following categorisation is proposed:

- Cost inference: a cost object's cost is a dependent variable with the propensity to be statistically related to the attributes characterising an instance of such an object. Following the rationale that the forecast generation is from past outturns, cost inference models require historical records for the dependent and independent variables involved, making no explicit connection to the company-specific processes;

- Cost attribution: causal understanding is developed prior to the cost estimate by relating an output to the input quantities that are, or must have been, consumed for the output to be achieved. Within cost attribution models, money serves as a meta-language, providing a value representation of the quantified flow of goods and services within the enterprise (van der Merwe, 2007).

Cost attribution models are sometimes criticised for being unable to allow for those costs that cannot be identified at the time of making a cost estimate. Cost inference models, by contrast, sacrifice causal explanation facilities assuming that unforeseen costs can be captured if past outturn costs are addressed in aggregate (Pugh et al., 2010).

The understanding of what is 'cost' can also vary (Cooper, 1990):

- Spending models identify cost with a measure of disbursement (cash outflows or expenditures) necessary to acquire resources. Such a measure is related directly and exclusively to a specific cost object (one unit of product, one fiscal year etc.). Cost inference models, as well as some cost attribution models exhibit a spending orientation.

- Resource consumption models understand cost as a measure of how the services of the resources acquired are engaged to attain some level of accomplishment of the enterprise as a whole. Any aspect affecting the flow of goods and service within the enterprise is relevant, even if it does not directly and immediately affect cash flows or expenditures. 
Finally, non-monetary metrics are commonly employed in order to attribute a monetary value to relationships'. However, these expressions are often a source of confusion (Stump, 1989). A comprehensive classification of such metrics would be difficult. Here, a logical grouping based on the cost object they identify is suggested:

- Design-related metrics establish equivalence between a platform-level design and its quantifiable characteristics through continuous variables such as weight and reliability, categorical variables and technometrics (Coccia, 2005);

- Unit-related metrics establish equivalence between a unit of product or service and its inputs. Typical examples include direct materials and labour (Hansen and Mowen, 2003);

- Time-related metrics establish equivalence between a time-span, the amount of inputs, and one or more product or service outputs. For example, an aircraft fleet fuel consumption and the hours flown in a calendar year;

- Process-related metrics quantify the outputs supplied and inputs demanded by each process operating within the relevant boundaries, whereby any process' outputs may be inputs to any other process, for example material and energy flows (Möller, 2010).

Design, unit, and time-related metrics mostly rely on technical knowledge, that is, knowledge about a specific technical system, how it operates and fails (Veldman et al., 2011). Process-related metrics rely on technological knowledge, as they emphasise an externalised understanding of the relationships between the inputs and outputs of a transformation operated the internal structure of which is only partly known (Bohn, 1994).

Differences in cost modelling rationale, underlying concept of cost and use of non-monetary metrics underpin the third challenge.

The unresolved debate opposing cost inference and cost attribution models, and the metrics deemed relevant in each, has been extended to the specific case of a PSS (Huang et al., 2012). However, cost attribution models based on resource consumption have been invoked in the service industry where the performance and cost of business processes, especially those experienced directly by customer, is crucial for competitive differentiation (Edwards, 1999). These models would allow a formalised representation of the functions and entities delivering value to the customer through human activities and product behaviour through a PSS (Kimita et al., 2009). 
Whilst it is recognised that successful service delivery requires measures focused on outcomes, cascaded throughout the service delivery system, when it comes to availability most research relies on product-related metrics such as Mean Time Between Failure, and Mean Time To Repair (see for example, Baines and Lightfoot, 2013). These metrics are recurrent in the maintenance performance literature (Simões et al., 2011) but provide little insight into how reliability and availability improvements can be achieved in managing the maintenance process (Smith and Mobley, 2007).

Finally, for computational purposes the relevant metrics can be associated with uncertainty. Uncertainty is associated with something not known with certainty, as opposed to the unknown and is intertwined with a state of loose cause-and-effect relationships that includes both fuzziness and ambiguity (Emblemsvåg, 2011). A probabilistic approach to uncertainty can only address situations characterised by an ambiguity which is due to conflicting beliefs about mutually exclusive alternatives. This uncertainty is said to have an aleatory nature and is identified with inherent variability quantified in terms of consequences and likelihood through absolute counting (Goh et al., 2010). Non-probabilistic approaches such as possibility and subjective probability theory can address fuzziness and other, nonspecific ambiguities. However, most of the identified sources of uncertainty in delivering such services as assets' availability are aleatory in nature (Erkoyuncu et al., 2011b).

The above said can be summarised in the following proposition:

Proposition 3: Costing an advanced service delivered through a PSS is a problem of attributing the value of means to the economic activities carried out for the ends to be achieved. Cost results from the interplay between monetary and non-monetary metrics, and uncertainties thereof.

In considering this proposition and the computational aspects previously identified (Figure 10), the literature on TLC has been analysed. Excluding conceptual works, computational detail is undisclosed or disclosed but not replicable in $70.2 \%$ of the quantitative works, confirming that the methods used in TLC are often unsatisfactory (Korpi and Ala-Risku, 2008).

\section{INSERT Figure 10 HERE}

The computational approaches employed in TLC can be identified as combinations of the aspects discussed above. These are illustrated in Figure 11 and described in Table 4. For example, a Cost Breakdown Structure is identified in Figure 11 through the coordinates 'spending' as underlying concept of cost, 'attribution' as modelling rationale, and 'unit-related' as non-monetary metrics. 
INSERT Figure 11 HERE

\section{INSERT Table 4 HERE}

Figure 12 shows the combinations of computational approaches in the reviewed literature.

\section{INSERT Figure 12 HERE}

Only $7.9 \%$ of the total cases were classified as means-ends TLC models, $5.9 \%$ of which are conceptual. Amongst quantitative works, the main contribution is Activity-based Life Cycle Costing (Emblemsvåg, 2003). Claims about Activity-Based Costing ( $A B C$ ) are made in $20 \%$ of cases which either disclose no computational details (Prabhakar and Sandborn, 2012) or consist in fact of a direct cost breakdown (Kayrbekova et al., 2011). The remaining 92.1\% (97.3\% of quantitative TLC models) focus on a concept of cost as a measure of spending rather than of resource consumption, drawing on the 'direct variable' cost encountered only because an asset is being built or used (Fiorello, 1975). Within these studies one or more of the following cost objects is assessed separately:

- A time interval: it may be directly associated with cash flows that are given (12.9\%), or inferred statistically or via Case Based Reasoning (7.9\%). Alternatively, it is broken down into given amounts of inputs (17.8\%), see for example Hunkeler et al. (2008), and outputs (4\%) used for cost normalisation. For reliability-based TLC models (40.6\%) the breakdown consists of the number of occurrences of product-sustaining events over a time-span. Finally, a combined assessment is used in $4.9 \%$ of cases, none of which are quantitative;

- A standalone instance. This can be further specified as:

- A product platform: The cost of designing and developing a product platform is considered in $4.9 \%$ of cases, $3 \%$ of which through statistical inference or Case Base Reasoning and 1\% through Cost Breakdown Structure (CBS);

- A product unit: The cost of a product unit is assessed in $27.7 \%$ of cases. Of these, 42.8\% employ CBS; $7.1 \%$ a genetic causative approach; $17.8 \%$ statistical inference; $10.7 \%$ Case Base Reasoning; and $21.4 \%$ (mostly conceptual) a combined assessment.

- An individual product-sustaining service: The cost of an individual productsustaining service is assessed in $17.8 \%$ of cases. Of these, $55.6 \%$ use a CBS, for example Kayrbekova et al. (2011). A service CBS approach has also been suggested to deal with a PSS in the context of availability contract (Datta and 
Roy, 2010); 11.1\% use Case Base Reasoning, for example, Romero Rojo et al. (2012) propose a model of avionic obsolescence cost for use in PSS contracts, in which the base cost of resolving an obsolescence issue must be known; the same number of cases features statistical inference, and combined assessment. Only one reference applies the genetic causal approach to service cost estimation (Early et al., 2012).

A variety of non-monetary metrics amongst those mentioned earlier in this section can be involved in a TLC study, and used directly in cost computation. Process-related metrics are only used in two of the cases reviewed for the purposes of means-ends costing. Platform-level metrics, which include reliability and maintainability metrics, feature in $75.7 \%$ of the cases; time-related metrics feature in $85.1 \%$ of cases normally relate to support occurrence; unit-related metrics in $33.8 \%, 48 \%$ of which concern direct inputs per unit of product-sustaining service.

Complementary non-monetary metrics may be derived from some of the primary metrics or obtained separately from TLC. For example, in Alonso et al. (2007) environmental performance metrics obtained through a Life Cycle Assessment are combined with TLC without otherwise overlapping. Similarly, equipment efficiency (Heilala et al., 2007) cost effectiveness (Blanchard, 1992), and affordability (Bankole et al., 2012) are obtained from the juxtaposition of separately determined cost and technical performance metrics related to an asset.

Availability features explicitly as a derived metric in $24 \%$ of cases. Availability is typically derived from design-related reliability (uptime) and maintainability (downtime) measures. These metrics are then used to solve optimization problems in parallel with TLC, such as: "given a specified level of asset availability, minimize the total cost of buying spare parts"; and "given a certain amount of money for buying spare parts, maximize the availability of the asset" (Ntuen and Moore, 1986). In $4 \%$ of cases, specific to the context of availability or performance-based contracts, availability concerns spare inventories and backorders, see for example Nowicki et al. (2008).

In the field of reliability engineering, a TLC model for an asset that operates and fails in unpredictable manner is also stochastic, the times to failure and to restore to operation being described by probability distributions that are known or knowable (Ntuen and Moore, 1986). In 45.9\% of the cases a probabilistic approach to uncertainty is adopted; only two studies refer to subjective probability (Erkoyuncu et al., 2011a; Emblemsvåg and Tonning, 2003); the remaining cases are deterministic. None of the reviewed cases address uncertainties by means of imprecise probability as suggested by Goh et al. (2010). Random event generation, mainly product-sustaining 
events, features mostly stochastic processes (12.2\%) and discrete event simulation (22.9\%). Agent based modelling has also been suggested in the context of availability-based contracts (Roy and Erkoyuncu, 2011). However, the authors provide only a top-level description of the proposed model.

Finding 3 Current approaches to TLC directly and immediately assign a measure of spending to an individual instance of product, service or time through non-monetary metrics expressing technical knowledge about the product. Uncertainty is addressed in terms of time distributions describing how an asset operates, fails and is restored to operation.

\section{Discussion}

The challenges and findings from the previous section are summarised in Table 5 highlighting the potential gaps. The cost of providing an advanced service, for example availability, through a PSS is the cost of either doing something 'right' from the customer's point of view (hence delivering value 'in use' through an outcome), or dealing with the consequences of failing to do so. This requires a formulation of cost assessment as a problem of attributing the value of means to the economic activities carried out for the ends to be achieved. By contrast, current approaches to TLC do not deal explicitly with the attribution problem, rather, performance (for example, availability) and cost are properties designed into an asset. This promotes a partial view in which individual cost objects are stripped of their context, and the analysis is then carried out assuming all things being equal.

\section{INSERT Table 5 HERE}

Rejecting a partial view requires a conceptualisation of TLC which assesses cost as an emergent property of the context within which multiple, potentially interacting products and services are designed and delivered simultaneously. From a modelling perspective, this requires a consistent and transparent representation of that context so that the interrelated consequences of changes in context can be translated into appropriate cost metrics (Field et al., 2007).

Few attempts have been made to question and substantially enrich the overall approach to TLC. Prasad (1999) discusses through-life performance metrics at a conceptual level, showing that the analysis should extend beyond the individual product item and also beyond the individual organisation's boundaries. Lindholm and Suomala (2007) recognise the importance of understanding maintenance and utilisation activities to improve "cost consciousness" i.e., awareness of the cost implications of the actions taken, after a purchase decisions is made. They advise using TLC in a continuous manner for cost monitoring. However, their focus is placed only on direct costs. Emblemsvåg (2003) provides an activity-based approach to TLC. By identifying key value creating 
activities within and across the organisational boundaries, the approach addresses interdependence related to reliability engineering are not addressed in-depth. Another approach, Total Cost of Ownership (TCO), addresses all the costs of doing business with specific suppliers with the aim of removing inefficiencies while maintaining or enhancing effectiveness (Ellram, 1996). Mévellec and Perry (2006) suggest avoiding lack of transparency in TLC by highlighting the interrelations between the costs incurred within the network of partners involved in enabling the customer to use the services of a product. However, no computational counterpart is provided.

Although not working on cost assessment, Heijungs (2001) proposes a methodology to deal with the attribution problem based on a consistent analytical representation of an economic process as the building block, and rules to determine how processes are to be clustered into systems of economic activities. Settanni et al. (2011) outline an analogous approach to introduce a whole system view in the computational structure of TLC. Building on such an approach, a methodology of TLC for use in PSS can be conceptualised as four steps shown in Figure 13 and described below.

\section{INSERT Figure 13 HERE}

\subsection{Functional unit identification}

PSS is an open system so the first step is to identify what constitutes the exogenously imposed demand for the system's deliverables. The delivery system's quantified performance in fulfilling its identified functions is called a functional unit. Originally developed in the field of Life Cycle Assessment (LCA), the term functional unit denotes the service which is expected to be rendered by a final consumption process (BS EN ISO, 2006). Analytically, a functional unit (e.g., passenger transportation for $1 \times 10^{3} \mathrm{~km}$ ) must translate into one or more modes of realisation of the servicedelivering flow (e.g., $1 \times 10^{3} \mathrm{~km}$ car-driving; $1 \times 10^{3} \mathrm{~km}$ train journey etc.).

Lindahl et al. (2014) specify modes of realising the functional units for some PSS case studies. However, only top-level, descriptive insight regarding the modes of supplying the functional units is provided.

In principle, availability can be thought of in terms of providing a result of value to a final customer, hence as an advanced service. For example, BAE System defines an available aircraft as one which is "...on the apron in a fit state for the men and women of Air Force to fly" (BAE Systems, 2009). However, formulating the appropriate functional unit is not straightforward, since availability - be it instantaneous, steady-state or mean availability (BS EN, 2009) - is typically thought of in 
terms of attributes designed into a product at the design phase, rather than in terms of a service(whole aircraft or LRU), or sub-items, as stocks of equivalent flyable hours (sorties, cycles etc.) through a common fictitious metric called 'capability units' so that the flows through the PSS to the exogenous demand can be thought of in terms of demand and supply of capability units, rather than individual items.

\subsection{Scope and boundaries definition}

The definition of boundaries and scope of the analysis draws a distinction between what is exogenous and what is endogenous to the delivery system and clarifies the level of granularity in examining what happens within those boundaries. Phenomena taking place outside the defined boundaries are deemed exogenous to the system, hence uncontrollable and subject to forecasting rather than decision making (Makridakis et al., 1998).

Valerdi et al. (2009) discuss the use of boundaries to clearly define the enterprise as a 'system' which extends beyond traditional organizational or inter-departmental boundaries. The aim is to assist researchers in identifying the appropriate scope of their respective research and to assist practitioners in bounding problems and identifying critical issues.

Within defined boundaries a service delivery system can be thought of as the occurrence of actions performed and managed by people in organizations, the outcomes of such actions, and the relationships between them. This view is consistent with the concept of 'system life cycle model' in the BS ISO/IEC 15288 standard on system engineering (BS ISO/IEC, 2002). However, in system science a system is an object perceived by people, hence forming a representation of the system whilst distinguishing between the system and its surroundings is inherently difficult and involves a degree of subjectivity (Flood and Carson, 1988).

\subsection{Knowledge elicitation and visualisation}

The analysis presented in section 4 shows that the current approaches to TLC focus on technical knowledge about an instance of product (hardware). However, architectural/physical entities constitute only one of the multiple, interrelated domains an engineering system spans across (Bartolomei et al., 2012). Situations involving socio-technical system, and hence human activity systems, are likely to be ill-defined, because complex and messy. In these situations emphasis is on building a defensible intellectual constructs to be used to represent such situation through a conceptual model, for example via Soft Systems Methodology (Wilson, 2001). 
Qualitative methods are used for the elicitation of the necessary knowledge to formally represent

a delivery system, in particular a PSS. Interviews are particularly suitable in applications concerning cost and performance estimation, where the key points of knowledge required involve not only what is done but also how and why (Naylor et al., 2001). Visualisation through pictures and diagrams then facilitates communication to achieve a shared understanding among a larger group about the same problem domain (Conklin, 2006). For example, an IDEFO diagram produces a structured representation of the activities or processes within the modelled system or subject area, depicting how they interrelate and operate. This can be used to provide a common "baseline" for communication across individual organisational units (NIST, 1993). The Functional Resonance Analysis Method (FRAM) is an approach developed for accident investigation and risk analysis, providing insight into why and how socio-technical systems normally succeed and occasionally fail (Hollnagel, 2012).

\subsection{Integrated system and cost modelling}

The application of qualitative methods provides an understanding of how the actions undertaken within the boundaries of the enterprise deliver advanced services, such as availability. The application of quantitative methods provides a mathematically treatable counterpart of the qualitative system representation, preserving the system structure in terms of dependencies and interdependencies. TLC is then conceptualised as a value representation of the system of interest. The necessary information has a dual nature (van der Merwe, 2007):

- A quantitative model of the flow of goods and services highlighting interlinked means, processes and ends within defined boundaries; and

- A corresponding value representation of these means-ends relationships, with monetary metrics serving as a meta-language to express the flow of goods and services.

Whilst methods or techniques for modelling PSS are available in the literature, scant attention has been given to the qualification of PSS as a 'system', as well as to capturing its dynamic behaviour over time (Cavalieri and Pezzotta, 2012). Also, to invoke a system approach to PSS, e.g., via diagrammatic process models, does not guarantee per se that the system architecture plays an explicit role in computing the cost of the service delivered (see for example, Kimita et al., 2009).

An appropriate way of dealing analytically with service costing, whilst preserving the structure of the underpinning delivery system, is through Input-Output Analysis (IOA). IOA is a method originally developed for modelling the operation of an economic system in an integrated way (Leontief, 1986). The building blocks can be as aggregated as whole industrial sectors within national economies, or as 
granular as individual processes within an enterprise. Applications of IOA outside macroeconomics include for example production-inventory systems modelling (Grubbstrom and Tang, 2000), product costing (Boons, 1998) and environmental life-cycle costing (Settanni and Emblemsvåg, 2010; Settanni et al., 2011). Whilst the basic IOA does not explicitly consider the temporal hierarchy of economic activity, the analytical treatment of timing aspects is critical since time lag in delivery is typically part of availability-based contracting. To address this shortcoming, Settanni et al. (2013) suggest modelling a PSS evolving over time analogously to an input-output production-inventory system to account for interdependencies.

\section{Conclusion}

This paper has investigated the extent to which current approaches to TLC provide sufficient methodological foundations for estimating the cost of delivering advanced services such as availability through a product-service-system. The main motivation to undertake this research has been to provide a well-defined concept of TLC for use in contracting for availability. Too often, 'faith' that a candidate product technology alone will reduce cost is the result of a lack of descriptive and analytical power in the cost analysis (Davis et al., 2003). Avoiding such shortcomings is particularly important in the context of PSS, since what counts is neither the individual asset nor service, but the socio-technical system delivering results of value for the customer.

The methodological challenges for the prevailing approaches to TLC within a context where advanced services are offered through a PSS have been identified and assessed through a systemic review of the public domain literature. TLC is an enduring concept for which authors tend to assume is methodologically homogeneous across the literature. This assumption only becomes obvious when the literature is examined from multiple domains.

It is the authors' opinion that those engaged in through-life cost estimation for PSS will find very limited guidance in the methods adopted in the reviewed literature on TLC due to methodological heterogeneities and terminological ambiguities (e.g., for terms such as cost, cash flows, and expenses; cost drivers and CERs; 'system' and PSS; processes; and life cycle). Also, the current debate around the estimation of the through-life cost for providing a service centres on the adaptation of established product cost estimation techniques, with a restrictive interpretation of the concept of life cycle. As a consequence cost estimation for a PSS is reduced to estimating the cost of the in-service phase of a durable product, not the cost of delivering advanced services through a socio-technical system. 
The research presented in this paper provides directions for future research through the formulation of a methodology of TLC for use in a PSS which addresses the main methodological challenges arising from the evidences found in the literature:

- Cost object (What): the proposed methodology is grounded on a representation of a PSS as a socio-technical 'system' delivering value in-use, and preserves its structure in order to handle multiple interacting cost objects simultaneously.

- Scope and purpose (Why?/To what extent?): the proposed methodology shifts emphasis from one-off should-cost estimating to through-life cost consciousness, enabling a systematic understanding of the functioning of the system being modelled as a basis to decide what action could be taken. It allows consistently expanding the boundaries of the analysis beyond the "four walls" of the individual firm to improve the visibility of end-to-end operations.

- Computations and metrics (How?): the proposed methodology formally and transparently addresses the interplay between monetary and non-monetary metrics. Reciprocal influences between multiple outcomes delivered by a system of purposeful activities are taken into account through a structure in which the relevant metrics and uncertainties thereof can be conveniently organised and simultaneously treated analytically.

In particular, it is recognised that qualitative methods must be employed to provide an understanding of how the actions undertaken within the boundaries of the enterprise enable or prevent the delivery of advanced services through a PSS. Quantitative methods must offer a mathematically treatable counterpart of a qualitative PSS representation, preserving the system structure in terms of dependencies and interdependencies. The principles of IOA originally developed in macroeconomics provide a suitable foundation for dealing analytically with a system of interdependent economic activities expressed as both monetary and non-monetary information, without requiring a priori commitment to a specific modelling language or a specific Information System to be already in place.

The proposed methodology of TLC emphasises aspects that could be better exploited if the estimate of the cost of an advanced service delivered by such a system is integrated, from a computational perspective, with by a model of the operation of the delivery system itself - the PSS. However, some caveats are necessary:

- In the literature, 'activities' or 'processes' often serve as cost categories, whilst ignoring the logical relationships between them from an analytical viewpoint. Hence, invoking 
approaches such as Activity Based Costing in TLC is not sufficient per se to guarantee that the nature of PSS as a socio-technical system is adequately addressed.

- The proposed methodology best operates under contractual conditions that encourage transparency and clarity of mutual commitments. Nicolini et al. (2000) outline the limitations of implementing strategic-orientated approaches to cost in contexts where a lack of trust and transparency is deep-seated within the industry's culture and practices. The move towards availability contracting should provide the cooperative environment which is necessary for approaches such as TLC to work (Seuring and Goldbach, 2002).

- To achieve cost reductions beyond the possibilities of individual organisations within the enterprise, information asymmetry between the customer and the provider regarding the relationship between the specifications established by the former and the resulting costs at the latter, should be reduced (Cooper and Slagmulder, 2004b).

The research presented in this paper strengthens the concept of TLC as a cost engineering and management practice by addressing some of the ambiguities and inconsistencies of current approaches in terms of boundaries and scope, metrics and cost objects involved. This provides a foundation for future research on TLC that is capable of effectively directing the attention of the decision maker towards the enabling conditions for the successful provision of such an advanced service as availability through a PSS.

\section{Appendix}

\section{INSERT Tables A.1 to A.6 HERE}

\section{References}

Aguilar-Saven, R.S., 2004. Business process modelling: Review and framework. International Journal of Production Economics 90 (2), 129-149.

Alonso, J.C., Dose, J., Fleischer, G., Geraghty, K., Greif, A., Rodrigo, J., Schmidt, W.-P., 2007. Electrical and electronic components in the automotive sector: Economic and environmental assessment. International Journal of Life Cycle Assessment 12 (5), 328-335.

Anagboso, M., Spence, A., 2009. Measuring Defence. Economic \& Labour Market Review 3 (1), 4452.

Asiedu, Y., Gu, P., 1998. Product life cycle cost analysis: State of the art review. International Journal of Production Research 36 (4), 883-908.

Assaf, S.A., Al-Hammad, A., Jannadi, O.A., Abu Saad, S., 2002. Assessment of the Problems of Application of Life Cycle Costing in Construction Projects. Cost Engineering 44 (2), 17-22. 
BAE Systems, 2009. Availability contracting: MAS procurement handbook. Lancashire: BAE Systems Plc.

Baines, T., Lightfoot, H., 2013. Made to serve: How manufacturers can compete through servitization and product-service systems. Hoboken, NJ, Chichester: Wiley.

Bankole, O.O., Roy, R., Shehab, E., Cheruvu, K., Johns, T., 2012. Product-service system affordability in defence and aerospace industries: state-of-the-art and current industrial practice. International Journal of Computer Integrated Manufacturing 25 (4-5), 398-416.

Bartolomei, J.E., Hastings, D.E., Neufville, R. de, Rhodes, D.H., 2012. Engineering Systems MultipleDomain Matrix: An organizing framework for modeling large-scale complex systems. Systems Engineering 15 (1), 41-61.

Batista, L., Smart, A., Maull, R., 2008. The systemic perspective of service processes: underlying theory, architecture and approach. Production Planning \& Control 19 (5), 535-544.

Blackwell, P., Hausner, E., 1999. The redefinition of supportability and its role as a systems engineering tool. Naval Engineers Journal 111 (3), 269-277.

Blanchard, B.S., 1992. Logistics engineering and management, 4th ed. Englewood Cliffs, NY: PrenticeHall.

Bohn, R.E., 1994. Measuring and Managing Technological Knowledge. Sloan Management Review 36 (1), 61-73.

Boons, A.N.A.M., 1998. Product costing for complex manufacturing systems. International Journal of Production Economics 55 (3), 241-255.

Bowman, R.A., Schmee, J., 2001. Pricing and managing a maintenance contract for a fleet of aircraft engines. Simulation 76 (2), 69-77.

Brode, H., 1975. Cost of Ownership - An overview. Life Cycle Costs: evaluation of avionic system reliability improvements. In: Proceedings of the Annual Reliability and Maintainability Symposium, Washington, DC, 28-30 January 1975, 212-216.

BS EN, 2005. 60300-3-3:2004 Dependability management. Part 3-3: Application guide - Life cycle costing. London: BSI.

BS EN, 2009. 60300-3-4:2008 Dependability management. Application guide. Guide to the specification of dependability requirements. London: BSI.

BS EN IEC, 2009. 0300-3-16:2008 Dependability management. Application guide. Guidelines for specification of maintenance support services. London: BSI.

BS EN ISO, 2006. 14040:2006 Environmental management. Life cycle assessment. Principles and framework. London: BSI.

BS ISO/IEC, 2002. 15288:2002 Systems engineering. System life cycle processes. London: BSI.

Buderath, M., 2011. The management of reliability and maintainability and the choice of maintenance concept to optimize aircraft availability and life cycle cost. In: RTO (Ed.). Enhanced aircraft platform availability through advanced maintenance concepts and technologies. Neuillysur-Seine CEDEX, France: NATO, Research and Technology Organisation, 9.1-9.24.

Burridge, J., Coyle, J., 2003. OSCAM - simulating Operation and Support Costs using system dynamics. In: Cost Structure and Life Cycle Cost (LCC) for Military Systems. Neuilly-sur-Seine CEDEX, France: NATO, Research and Technology Organisation, 9.1-9.10.

Caldwell, N.D., Settle, V., 2011. Incentives and contracting for availability: procuring complex performance. In: Ng, I.C.L., Parry, G.C., Wild, P., McFarlane, D., Tasker, P. (Eds.). Complex engineering service systems. Concepts and research. Berlin: Springer, 147-160. 
Cavalieri, S., Pezzotta, G., 2012. Product-Service Systems Engineering: State of the art and research challenges. Computers in Industry 63 (4), 278-288.

Chen, S., Keys, L.K., 2009. A cost analysis model for heavy equipment. Computers \& Industrial Engineering 56 (4), 1276-1288.

Cheung, W.M., Marsh, R., Newnes, L.B., Mileham, A.R., Lanham, J.D., 2009. Standards and inference of design information in through-life costing of innovative defence electronic products. Proceedings of the Institution of Mechanical Engineers, Part B: Journal of Engineering Manufacture 223 (2), 169-181.

Christensen, P.N., Sparks, G.A., Kostuk, K.J., 2005. A method-based survey of life cycle costing literature pertinent to infrastructure design and renewal. Canadian Journal of Civil Engineering 32 (1), 250-259.

Cinquini, L., Tenucci, A., 2010. Strategic management accounting and business strategy: a loose coupling? Journal of Accounting \& Organizational Change 6 (2), 228-259.

Clinton, B.D., Graves, A.H., 1999. Product value analysis: Strategic analysis over the entire product life cycle. Journal of Cost Management 3 (3), 22-29.

Coccia, M., 2005. Technometrics: Origins, historical evolution and new directions. Technological Forecasting and Social Change 72 (8), 944-979.

Conklin, E.J., 2006. Dialogue mapping: Building shared understanding of wicked problems. Chichester, Hoboken, NJ: Wiley.

Cooper, R., 1990. Explicating the logic of ABC. Management Accounting 68 (10), 58-60.

Cooper, R., Slagmulder, R., 2004a. Achieving full-cycle cost management. Sloan Management Review 46 (1), 45-52.

Cooper, R., Slagmulder, R., 2004b. Interorganizational cost management and relational context. Accounting Organizations and Society 29 (1), 1-26.

Cople, D.G., Brick, E.S., 2010. A simulation framework for technical systems life cycle cost analysis. Simulation Modelling Practice and Theory 18 (1), 9-34.

Curran, R., Gomis, G., Castagne, S., Butterfield, J., Edgar, T., Higgins, C., McKeever, C., 2007. Integrated digital design for manufacture for reduced life cycle cost. International Journal of Production Economics 109 (1-2), 27-40.

Curran, R., Raghunathan, S., Price, M., 2004. Review of aerospace engineering cost modelling: The genetic causal approach. Progress in Aerospace Sciences 40 (8), 487-534.

Curry, E.E., 1993. FALCCM-H: Functional Avionics Life Cycle Cost Model for Hardware. In: Proceedings of the IEEE National Aerospace and Electronics Conference, Dayton, OH, 24-28 May 1993, 950-953.

Dahlén, P., Bolmsjö, G.S., 1996. Life-cycle cost analysis of the labor factor: Proceedings of the 8th International Working Seminar on Production Economics. International Journal of Production Economics 46-47, 459-467.

Datta, P.P., Roy, R., 2010. Cost modelling techniques for availability type service support contracts: A literature review and empirical study. CIRP Journal of Manufacturing Science and Technology 3 (2), 142-157.

Davis, N., Jones, J., Warrington, L., 2003. A framework for documenting and analyzing life-cycle costs using a simple network based representation. In: Proceedings of the Annual Reliability and Maintainability Symposium, Tampa, FL, 27-30 January 2003, 232-236. 
Dean, E.B., 1993. Why Does It Cost How Much? In: Proceedings of the AIAA Aircraft Design, Systems, and Operations Meeting, Monterey, CA, 11-13 August 1993. doi: 10.2514/6.1993-3966.

Debardelaben, J.A., Madisetti, V.K., Gadient, A.J., 1997. Incorporating cost modeling in embeddedsystem design. IEEE Design \& Test of Computers 14 (3), 24-35.

Degraeve, Z., Roodhooft, F., Doveren, B. van, 2005. The Use of Total Cost of Ownership for Strategic Procurement: A Company-Wide Management Information System. The Journal of the Operational Research Society 56 (1), 51-59.

Dhillon, B.S., 1981. Life cycle cost: A survey. Microelectronics Reliability 21 (4), 495-511.

Dhillon, B.S., 2010. Life cycle costing for engineers. Boca Raton, FL: Taylor \& Francis.

Doost, R.K., 1996. Input, output, outcome: simply a change in orientation. Managerial Auditing Journal 11 (7), 12-15.

Dunk, A., 2004. Product life cycle cost analysis: the impact of customer profiling, competitive advantage, and quality of IS information. Management Accounting Research 15 (4), 401-414.

Durairaj, S.K., Ong, S.K., Nee, A.Y.C., Tan, R.B.H., 2002. Evaluation of Life Cycle Cost Analysis Methodologies. Corporate Environmental Strategy 9 (1), 30-39.

Early, J.M., Price, M.A., Curran, R., Raghunathan, S., 2012. Whole-Life Costing for Capability. Journal of Aircraft 49 (3), 712-723.

Edwards, J.B. (Ed.), 1999. Cost management for service industries. New York: Warren, Gorham \& Lamont.

Elford, D.G., 2011. The Evolution of Aircraft Support Concepts Within the UK MoD's Defence Logistics Transformation Programme. In: RTO (Ed.). Enhanced aircraft platform availability through advanced maintenance concepts and technologies. NATO, Research and Technology Organisation, 6.1-6.14.

Ellram, L.M., 1995. Total cost of ownership: an analysis approach for purchasing. International Journal of Physical Distribution \& Logistics Management 25 (8), 4-23.

Ellram, L.M., 1996. A Structured Method for Applying Purchasing cost Management Tools. International Journal of Purchasing \& Materials Management 32 (1), 11-19.

Emblemsvåg, J., 2003. Life-cycle costing: Using activity-based costing and Monte Carlo methods to manage future costs and risks. Hoboken, NJ: Wiley.

Emblemsvåg, J., 2011. Augmenting the Risk Management Process. In: Nota, G. (Ed.). Risk Management Trends. Rijeka, Croatia: InTech, 1-26.

Emblemsvåg, J., Tonning, L., 2003. Decision support in selecting maintenance organization. Journal of Quality in Maintenance Engineering 9 (1), 11-24.

Erkoyuncu, J.A., Roy, R., Datta, P.P., Wardle, P., Murphy, F., 2011a. Service uncertainty and cost for product service systems. In: Ng, I.C.L., Parry, G.C., Wild, P., McFarlane, D., Tasker, P. (Eds.). Complex engineering service systems. Concepts and research. Berlin: Springer, 129-146.

Erkoyuncu, J.A., Roy, R., Shehab, E., Cheruvu, K., 2011b. Understanding service uncertainties in industrial product-service system cost estimation. The International Journal of Advanced Manufacturing Technology 52 (9-12), 1223-1238.

Fabrycky, W.J., Blanchard, B.S., 1991. Life-cycle cost and economic analysis. Englewood Cliffs, NJ: Prentice Hall.

Feldman, K., Jazouli, T., Sandborn, P.A., 2009. A Methodology for Determining the Return on Investment Associated With Prognostics and Health Management. IEEE Transactions on Reliability 58 (2), 305-316. 
Ferrin, B.G., Plank, R.E., 2002. Total Cost of Ownership Models: An Exploratory Study. Journal of Supply Chain Management 38 (3), 18-29.

Field, F., Kirchain, R., Roth, R., 2007. Process cost modeling: Strategic engineering and economic evaluation of materials technologies. JOM Journal of the Minerals, Metals and Materials Society 59 (10), 21-32.

Fielding, J.P., 1999. Introduction to aircraft design. Cambridge: Cambridge University Press.

Fiorello, M.R., 1973. Problems in avionics life-cycle analysis. Santa Monica, CA: RAND Corporation.

Fiorello, M.R., 1975. Estimating Life-Cycle Costs: a case study of the A-7D R-1518-PR. Santa Monica, CA: RAND Corporation.

Fixson, S.K., 2004. Assessing product architecture costing: product life cycles, allocation rules and cost models. In: Proceedings of ASME 2004 Design Engineering Technical Conference, Salt Lake City, Utah. 28 September - 2 October 2004.

Flood, R.L., Carson, E.R., 1988. Dealing with complexity: An introduction to the theory and application of systems science. New York: Plenum Press.

Folgado, R., Peças, P., Henriques, E., 2010. Life cycle cost for technology selection: A Case study in the manufacturing of injection moulds: Integrating the Global Supply Chain. International Journal of Production Economics 128 (1), 368-378.

Galloway, I., 1996. Design for support and support the design: integrated logistic support - the business case. Logistics Information Management 9 (1), 24-31.

Geissdörfer, K., Gleich, R., Wald, A., 2009. Standardisierungspotentiale lebenszyklusbasierter Modelle des strategischen Kostenmanagements. Zeitschrift für Betriebswirtschaft 79 (6), 693715.

Gitzel, R., Herbort, M., 2008. Optimizing life cycle cost using genetic algorithms. Cost Management $22(6), 34-47$.

Goh, Y.M., Newnes, L.B., Mileham, A.R., McMahon, C.A., Saravi, M.E., 2010. Uncertainty in ThroughLife Costing - Review and Perspectives. IEEE Transactions on Engineering Management 57 (4), 689-701.

Grubbstrom, R.W., Tang, O., 2000. An Overview of Input-Output Analysis Applied to ProductionInventory Systems. Economic Systems Research 12 (1), 3-25.

Gupta, Y., Chow, W.S., 1985. Twenty-Five Years of Life Cycle Costing - Theory and Applications: A Survey. International Journal of Quality \& Reliability Management 2 (3), 51-76.

Gutschelhofer, A., Roberts, H., 1997. Anglo-Saxon and German life-cycle costing. The International Journal of Accounting 32 (1), 23-44.

Hansen, D.R., Mowen, M.M., 2003. Cost management: Accounting and control, 4th ed. Thomson/South-Western, Mason, Ohio, USA, xxii, 1029.

Hatch, M., Badinelli, R.D., 1999. A concurrent optimization methodology for concurrent engineering. IEEE Transactions on Engineering Management 46 (1), 72-86.

Heijungs, R., 2001. A theory of the environment and economic systems: a unified framework for ecological economic analysis and decision support. Cheltenham: Edward Elgar.

Heilala, J., Montonen, J., Helin, K., 2007. Selecting the right system - assembly system comparison with total cost of ownership methodology. Assembly Automation 27 (1), 44-54.

Hitt, E.F., 1997. Avionics cost of ownership. IEEE Aerospace and Electronic Systems Magazine 12 (11), 3-7. 
Hollnagel, E., 2012. FRAM, the functional resonance analysis method: Modelling complex sociotechnical systems. Ashgate, Farnham, Surrey, UK England, Burlington, VT, 142 pp.

Hoyle, C., 2013. UK reveals expenditure on delayed Watchkeeper programme. Flightglobal. http://www.flightglobal.com/news/articles/uk-reveals-expenditure-on-delayed-watchkeeperprogramme-380779/. [Accessed 8 January 2013].

Huang, X., Newnes, L.B., Parry, G.C., 2011. An analysis of industrial practice for estimating the inservice costs of a product service system. In Proceedings of the ASME International Design Engineering Technical Conferences (IDETC) and Computers and Information in Engineering Conference (CIE), Washington, DC, August 28-31, 2011.

Huang, X.X., Newnes, L.B., Parry, G.C., 2012. The adaptation of product cost estimation techniques to estimate the cost of service. International Journal of Computer Integrated Manufacturing 25 (45), 417-431.

Hunkeler, D., Lichtenvort, K., Rebitzer, G. (Eds.), 2008. Environmental life cycle costing. Pensacola FL, Boca Raton, SETAC; CRC Press.

Hwang, H.-S., 2005. Costing RAM design and test analysis model for production facility. International Journal of Production Economics 98 (2), 143-149.

Hypko, P., Tilebein, M., Gleich, R., 2010. Clarifying the concept of performance-based contracting in manufacturing industries: A research synthesis. Journal of Service Management 21 (5), 625-655.

Jackson, D.W., Ostrom, L.L., 1980. Life Cycle Costing in industrial purchasing. Journal of Purchasing and Materials Management 16 (4), 8-12.

Jambulingam, N., Jardine, A.K.S., 1986. Life Cycle Costing considerations in reliability centered maintenance: an application to maritime equipment. Reliability Engineering 15 (4), 307-317.

James, K.L., 2003. Environmental life cycle costs in the Australian food packaging supply chain. Dissertation, Victoria University of Technology, Australia.

Jazouli, T., Sandborn, P., 2011. Using PHM to meet availability-based contracting requirements. In: Proceedings of the Annual Conference of the Prognostics and Health Management Society, Montreal, Canada, 25-29 September 2011.

Kaenzig, J., Wüstenhagen, R., 2010. The Effect of Life Cycle Cost Information on Consumer Investment Decisions Regarding Eco-Innovation. Journal of Industrial Ecology 14 (1), 121-136.

Kayrbekova, D., Markeset, T., Ghodrati, B., 2011. Activity-based life cycle cost analysis as an alternative to conventional LCC in engineering design. International Journal of System Assurance Engineering and Management 2 (3), 218-225.

Keller, S., Collopy, P., Componation, P., 2014. What is wrong with space system cost models? A survey and assessment of cost estimating approaches. Acta Astronautica 93, 345-351.

Khan, K.A., Houston, G.D., 2000. Design optimization using Life Cycle Cost Analysis for low operating costs. In: Design for Low Cost Operation and Support. Neuilly-sur-Seine CEDEX, France: NATO Research and Technology Organisation, 8.1-8.8.

Kiang, T., 1979. The development and implementation of Life Cycle Cost methodology. In: Methodology for control of Life Cycle Costs for avionic systems. Neuilly-sur-Seine CEDEX, France: AGARD/NATO, 3.1-3.25.

Killingsworth, P., Jarvaise, J., 1990. VHSIC electronics and the cost of Air Force avionics in the 1990s. Santa Monica CA: RAND Corporation. 
Kilpatrick, P.S., Jones, A.L., 1974. Life Cycle Costs comparisons of avionic system design alternatives. In: Proceedings of the IEEE National Aerospace and Electronics Conference, Dayton, $\mathrm{OH}, 13-15$ May 1974, 514-520.

Kim, S.-H., Cohen, M.A., Netessine, S., 2007. Performance Contracting in After-Sales Service Supply Chains. Management Science 53 (12), 1843-1858.

Kim, Y. S., Lee, S. W., Jin, H., Shin, J. H., Park, J. A., Lee, Y. G., Kim, C. D., Seo, B. H., Lee, S. J. (2011): Product-Service Systems (PSS) design process and design support system. In Hesselbach, J., Herrmann, C. (Eds.). Functional thinking for value creation. Berlin, Heidelberg: Springer, 129134.

Kimita, K., Hara, T., Shimomura, Y., Arai, T., 2009. Cost evaluation method for service design based on Activity Based Costing. In: Proceedings of the 7th International Conference on Manufacturing Research, Warwick, 8-10 September 2009.

Kleyner, A., Sandborn, P., 2008. Minimizing life cycle cost by managing product reliability via validation plan and warranty return cost. International Journal of Production Economics 112 (2), 796-807.

Korpi, E., Ala-Risku, T., 2008. Life cycle costing: a review of published case studies. Managerial Auditing Journal 23 (3), 240-261.

Kumar, D.U., Nowicki, D., Ramirez-Marquez, J., Verma, D., 2007. A goal programming model for optimizing reliability, maintainability and supportability under performance based logistics. International Journal of Reliability, Quality and Safety Engineering 14 (3), 251-261.

Lad, B.K., Kulkarni, M.S., 2008. Integrated reliability and optimal maintenance schedule design: a Life Cycle Cost based approach. International Journal of Product Lifecycle Management 3 (1), 78-90.

Lanza, G., Ruhl, J., 2009. Simulation of service costs throughout the life cycle of production facilities. CIRP Journal of Manufacturing Science and Technology 1 (4), 247-253.

Leontief, W., 1986. Input-output economics, 2nd ed. New York: Oxford University Press.

Lindahl, M., Sundin, E., Sakao, T., 2014. Environmental and economic benefits of Integrated Product Service Offerings quantified with real business cases. Journal of Cleaner Production 64, 288-296. Lindholm, A., Suomala, P., 2002. Present and Future of Life Cycle Costing: Reflections from Finnish Companies. Liiketaloudellinen aikakauskirja: The Finnish Journal of Business Economics 54 (2), 282-292.

Lindholm, A., Suomala, P., 2007. Learning by costing: Sharpening cost image through life cycle costing? International Journal of Productivity and Performance Management 56 (8), 651-672.

Liu, H., Gopalkrishnan, V., Ng, W.K., Song, B., Li, X., 2008. An intelligent system for estimating full product Life Cycle Cost at the early design stage. International Journal of Product Lifecycle Management 3 (2/3), 96-113.

Löfstrand, M., Andrews, J., Karlberg. Magnus, Karlsson, L., 2012. Modelling and simulation of functional product system availability and support costs. International Journal of Product Development 16 (3/4), 304-326.

Lycette, B., Lowenstein, D., 2011. The real "Total Cost of Ownership" of your test equipment. IEEE Aerospace and Electronic Systems Magazine 26 (1), 40-44.

Makridakis, S.G., Wheelwright, S.C., Hyndman, R.J., 1998. Forecasting: Methods and applications, 3rd ed. New York: Wiley.

Marais, K.B., Saleh, J.H., 2009. Beyond its cost, the value of maintenance: An analytical framework for capturing its net present value. Reliability Engineering \& System Safety 94 (2), 644-657. 
Marks, K.E., Massey, H.G., 1981. A new approach for modeling the cost of ownership for aircraft systems: A project Air Force report. Santa Monica, CA: RAND Corporation.

McGuire, G.G., 1971. The Defense Department's use of discounting in the procurement of equipment by the Life Cycle Costing concept. Journal of Purchasing and Materials Management 7 (3), 41-55.

McNair, C.J., 1990. Interdependence and control: traditional vs. Activity-Based responsibility accounting. Journal of Cost Management 4 (2), 15-24.

Meier, H., Roy, R., Seliger, G., 2010. Industrial Product-Service Systems-IPS2. CIRP Annals Manufacturing Technology 59 (2), 607-627.

Mévellec, P., Perry, N., 2006. Whole life-cycle costs: a new approach. International Journal of Product Lifecycle Management 1 (4), 400-414.

Mirghani, M.A., 1996. Aircraft maintenance budgetary and costing systems at the Saudi Arabian Airlines: An integrated business approach. Journal of Quality in Maintenance Engineering 2 (4), 32-47.

Möller, A., 2010. Material and Energy Flow-Based Cost Accounting. Chemical Engineering \& Technology 33 (4), 567-572.

Mueller, D., 2009. Modelling trade-offs in design-accompanying life cycle cost calculation. International Journal of Product Lifecycle Management 4 (1-3), 290-310.

Nalos, E.J., Schulz, R.B., 1965. Reliability and Cost of Avionics: IEEE Transactions on Reliability 14 (2), 120-130.

Naylor, J.B., Griffiths, J., Naim, M.M., 2001. Knowledge-based system for estimating steel plant performance. International Journal of Operations \& Production Management 21 (7), 1000-1019.

Neely, A., Gregory, M., Platts, K., 2005. Performance measurement system design: A literature review and research agenda. International Journal of Operations \& Production Management 25 (12), 1228-1263.

Newnes, L.B., Mileham, A.R., Cheung, W.M., Marsh, R., Lanham, J.D., Saravi, M.E., Bradbery, R.W., 2008. Predicting the whole-life cost of a product at the conceptual design stage. Journal of Engineering Design 19 (2), 99-112.

Newnes, L.B., Mileham, A.R., Rees, G., Green, P., 2011. Costing for Avionic Through-Life Availability. In: Hesselbach, J., Herrmann, C. (Eds.), Glocalized Solutions for Sustainability in Manufacturing. Berlin: Springer, 675-680.

Ng, I.C.L., Parry, G.C., Wild, P., McFarlane, D., Tasker, P. (Eds.), 2011. Complex engineering service systems: Concepts and research. Berlin: Springer.

Nicolini, D., Tomkins, C., Holti, R., Oldman, A., Smalley, M., 2000. Can Target Costing and Whole Life Costing be Applied in the Construction Industry?: Evidence from Two Case Studies. British Journal of Management 11 (4), 303-324.

NIST, 1993. Integration definition for function modeling (IDEFO). National Institute of Standards and Technology, Draft Federal Information Processing Standards Publication 183.

Nowicki, D., Kumar, D.U., Steudel, H., Verma, D., 2008. Spares provisioning under performancebased logistics contract: profit-centric approach. Journal of the Operational Research Society 59 (3), 342-352.

Ntuen, C.A., 1985. Availability-based life cycle cost model: A simulation approach. Microelectronics Reliability 25 (2), 331-342. 
Ntuen, C.A., Moore, L., 1986. Approaches to life cycle cost analysis with system availability constraints - A review. Microelectronics Reliability 26 (2), 341-354.

Olubodun, F., Kangwa, J., Oladapo, A., Thompson, J., 2010. An appraisal of the level of application of life cycle costing within the construction industry in the UK. Structural Survey 28 (4), 254-265.

Öner, K.B.K.G.P., van Houtum, G.J., 2010. Optimization of component reliability in the design phase of capital goods. European Journal of Operational Research 205 (3), 615-624.

Park, J.-H., Seo, K.-K., 2004. Incorporating life-cycle cost into early product development. Proceedings of the Institution of Mechanical Engineers, Part B: Journal of Engineering Manufacture 218 (9), 1059-1066.

Perrigo, W., Easterday, L.J., 1974. Avionic equipment reliability and low life cycle cost. In: Proceedings of the IEEE National Aerospace and Electronics Conference, Dayton OH, 13-15 May 1974, 521-531.

Prabhakar, V.J., Sandborn, P., 2012. A part total cost of ownership model for long life cycle electronic systems. International Journal of Computer Integrated Manufacturing 25 (4-5), 384-397.

Prasad, B., 1999. A model for optimizing performance based on reliability, life-cycle costs and other measurements. Production Planning \& Control 10 (3), 286-300.

Pugh, P.G., Faddy, D., Curran, R., 2010. Project Management: Cost Analysis. In: Blockley, R., Shyy, W. (Eds.). Encyclopedia of Aerospace Engineering. Wiley.

Purchase, V., Parry, G.C., Valerdi, R., Nightingale, D., Mills, J., 2011. Enterprise Transformation: Why Are We Interested, What Is It, and What Are the Challenges? Journal of Enterprise Transformation 1 (1), 14-33.

Reimann, M.D., Huq, F., 1993. Using activity based costing to define a quantitative product life cycle cost model for concurrent engineering. In: Proceedings of the third international conference on Flexible Automation and Information Management, Limerick, Ireland.

Rhee, S.J., Ishii, K., 2003. Using cost based FMEA to enhance reliability and serviceability. Advanced Engineering Informatics 17 (3-4), 179-188.

Romero Rojo, F.J., Roy, R., Shehab, E., Cheruvu, K., Mason, P., 2012. A cost estimating framework for electronic, electrical and electromechanical (EEE) components obsolescence within the useoriented product-service systems contracts. Proceedings of the Institution of Mechanical Engineers, Part B: Journal of Engineering Manufacture 226 (1), 154-166.

Roskam, J., 1990. Airplane Design. Part VIII: Airplane Cost Estimation: Design, Development, manufacturing, and Operating. Lawrence, Kansas: The University of Kansas.

Roy, R., 2003. Cost engineering: why, what and how? Decision Engineering Report Series. Cranfield: Cranfield University.

Roy, R., Erkoyuncu, J.A., 2011. Service cost estimation challenges in Industrial Product-Service Systems. In: Hesselbach, J., Herrmann, C. (Eds.). Functional thinking for value creation. Berlin, Heidelberg: Springer, 1-10.

Ryan, E.T., Schubert Kabban, Christine M., Jacques, D.R., Ritschel, J.D., 2013. A Macro-Stochastic Model for Improving the Accuracy of Department of Defense Life Cycle Cost Estimates. Journal of Cost Analysis and Parametrics 6 (1), 43-74.

Sachdeva, A., Kumar, D., Kumar, P., 2008. Planning and optimizing the maintenance of paper production systems in a paper plant. Computers \& Industrial Engineering 55 (4), 817-829.

Sampson, S.E., 2012. Visualizing Service Operations. Journal of Service Research 15 (2), 182-198. 
Sandberg, M., Boart, P., Larsson, T., 2005. Functional Product Life-cycle Simulation Model for Cost Estimation in Conceptual Design of Jet Engine Components. Concurrent Engineering 13 (4), 331342.

Sandborn, P., 2013. Cost Analysis of Electronic Systems. Singapore: World Scientific Publishing.

Schor, A.L., Leong, F.J., Babcock, P.S., 1989. Impact of fault-tolerant avionics on life-cycle costs. In: Proceedings of the IEEE National Aerospace and Electronics Conference, Dayton, OH , 22-26 May 1989, 1893-1899.

Schulze, M., Seuring, S., Ewering, C., 2012. Applying activity-based costing in a supply chain environment. International Journal of Production Economics 135 (2), 716-725.

Seddon, J., O’Donovan, B., Zokaei, K., 2011. Rethinking Lean Service. In: Macintyre, M., Parry, G.C., Angelis, J. (Eds.). Service Design and Delivery. New York: Springer, 41-60.

Seger, J.K., 1983. Reliability Investment and Life-Cycle Cost. IEEE Transactions on Reliability R-32 (3), 259-263.

Settanni, E., 2008. The need for a computational structure of LCC. International Journal of Life Cycle Assessment 13 (7), 526-531.

Settanni, E., Emblemsvåg, J., 2010. Applying a non-deterministic conceptual life cycle costing model to manufacturing processes. Journal of Modelling in Management 5 (3), 220-262.

Settanni, E., Tassielli, G., Notarnicola, B., 2011. An Input-Output technological model of Life Cycle Costing: computational aspects and implementation issues in a generalised supply chain perspective. In: Burritt, R., Schaltegger, S., Bennett, M., Pohjola, T., Csutora, M. (Eds.). Environmental management accounting and supply chain management, Dordrecht: Springer, 55109.

Settanni, E., Thenent, N.E., Newnes, L.B., 2013. System modeling: a foundation for costing throughlife availability provision. In: Bernard, A., Rivest, L., Dutta, D. (Eds.). Product Lifecycle Management for Society. Berlin, Heidelberg: Springer, 48-57.

Seuring, S.A., Goldbach, M. (Eds.), 2002. Cost management in supply chains. Heidelberg: PhysicaVerlag.

Shank, J.K., Govindarajan, V., 1992. Strategic Cost Management and the value chain. Journal of Cost Management 5 (4), 5-21.

Sharma, D., Cui, Q., 2012. Design of Concession and Annual Payments for Availability Payment Public Private Partnership (PPP) Projects. In: Proceedings of the Construction Research Congress, West Lafayette, IN, 22-23 May 2012.

Sherif, Y.S., Kheir, N.A., 1982. Weapons systems analysis, part I: System effectiveness. Microelectronics Reliability 22 (3), 531-567.

Sherif, Y.S., Kolarik, W.J., 1981. Life cycle costing: Concept and practice. Omega 9 (3), 287-296.

Shields, M.D., Young, M.S., 1991. Managing product Life Cycle Costs: An organizational model. Journal of Cost Management 5 (3), 39-51.

Simões, J.M., Gomes, C.F., Yasin, M.M., 2011. A literature review of maintenance performance measurement: A conceptual framework and directions for future research. Journal of Quality in Maintenance Engineering 17 (2), 116-137.

Skwirzynski, J.K. (Ed.), 1983. Electronic Systems Effectiveness and Life Cycle Costing. Berlin, Heidelberg: Springer.

Smit, M.C., 2012. A North Atlantic Treaty Organisation framework for Life Cycle Costing: IInternational Journal of Computer Integrated Manufacturing 25 (4-5), 444-456. 
Smith, R., Mobley, R.K., 2007. Rules of Thumb for Maintenance and Reliability Engineers. Elsevier.

Stump, E.J., 1988. An application of Markov chains to life-cycle cost analysis. International Journal of

Production Economics 14 (2), 151-156.

Stump, E.J., 1989. “Cost Driver" Confusion. Journal of Parametrics 9 (3), 11-12.

Suwondo, E., 2007. LCC-OPS: Life cycle cost application in aircraft operations Bandung: ITB Press.

The Economist, Jul 30th 2011. A tale of two industries: The contrast between two adjacent factories

in an East Midlands town suggests how British manufacturing might prosper.

Thenent, N.E., Settanni, E., Newnes, L.B., 2012. Know what you need to know: The role of technological knowledge in product service systems. In: Proceedings of the ASME 2012 11th Biennial Conference on Engineering Systems Design and Analysis (ESDA2012), Nantes, 02-05 July 2012, 453-464.

Toohey, E., Calvo, A., 1980. Cost analyses for avionics acquisition. In: Proceedings of the Annual Reliability and Maintainability Symposium, San Francisco, CA, 22-24 January 1980, 85-90.

Tranfield, D., Denyer, D., Smart, P., 2003. Towards a Methodology for Developing Evidence-Informed Management Knowledge by Means of Systematic Review. British Journal of Management 14 (3), 207-222.

Tukker, A., Tischner, U., 2006. Product-services as a research field: past, present and future. Reflections from a decade of research. Journal of Cleaner Production 14 (17), 1552-1556.

Tuttle, D.E., Shwartz, M.N., 1979. Lower avionic temperature lower life cycle cost, in: Proceedings of the Annual Reliability and Maintainability Symposium 1979. In: Proceedings of the Annual Reliability and Maintainability Symposium, Washington, DC, 23-25 January 1979, 332-337.

Tysseland, B.E., 2008. Life cycle cost based procurement decisions. International Journal of Project Management 26 (4), 366-375.

Valerdi, R., Nightingale, D., Blackburn, C., 2009. Enterprises as systems: Context, boundaries, and practical implications. Information Knowledge Systems Management 7 (4), 377-399.

van der Merwe, A., 2007. Management accounting philosophy II: The cornerstones of restoration. Cost Management 21 (5), 26-33.

Veldman, J., Klingenberg, W., Wortmann, H., 2011. Managing condition-based maintenance technology: A multiple case study in the process industry. Journal of Quality in Maintenance Engineering 17 (1), 40-62.

Waghmode, L., Sahasrabudhe, A., 2011. Modelling maintenance and repair costs using stochastic point processes for life cycle costing of repairable systems. International Journal of Computer Integrated Manufacturing 25 (4-5), 353-367.

Wang, J., Wang H. F., Zhang, W.J., Ip W.H., Furuta, K., 2013. On a Unified Definition of the Service System: What is its Identity? IEEE Systems Journal doi:10.1109/JSYST.2013.2260623.

Webster, J., Watson, R.T., 2002. Analyzing the Past to Prepare for the Future: Writing a Literature Review. MIS Quarterly 26 (2), xiii-xxiii.

Wilson, B., 2001. Soft systems methodology: Conceptual model building and its contribution Chichester, New York: Wiley.

$\mathrm{Wu}, \mathrm{S}$., Longhurst, P., 2011. Optimising age-replacement and extended non-renewing warranty policies in lifecycle costing. International Journal of Production Economics 130 (2), 262-267.

Xu, X., Chen, J.L.-Q., Xie, S.Q., 2006. Framework of a Product Lifecycle Costing System. Journal of Computing and Information Science in Engineering 6 (1), 69-77. 
Xu, Y., Elgh, F., Erkoyuncu, J.A., Bankole, O., Goh, Y.M., Cheung, W.M., Baguley, P., Wang, Q., Arundachawat, P., Shehab, E., Newnes, L.B., Roy, R., 2012. Cost Engineering for manufacturing: Current and future research. International Journal of Computer Integrated Manufacturing 25 (45), 300-314.

Xu, Y., Wang, J., Tan, X., Curran, R., Raghunathan, S., Doherty, J., Gore, D., 2008. A generic Life Cycle Cost modeling approach for aircraft system. In: Curran, R., Chou, S.-Y., Trappey, A. (Eds.). Collaborative Product and Service Life Cycle Management for a Sustainable World. London: Springer, 251-258. 
Figure 1: Research strategy

Click here to download high resolution image

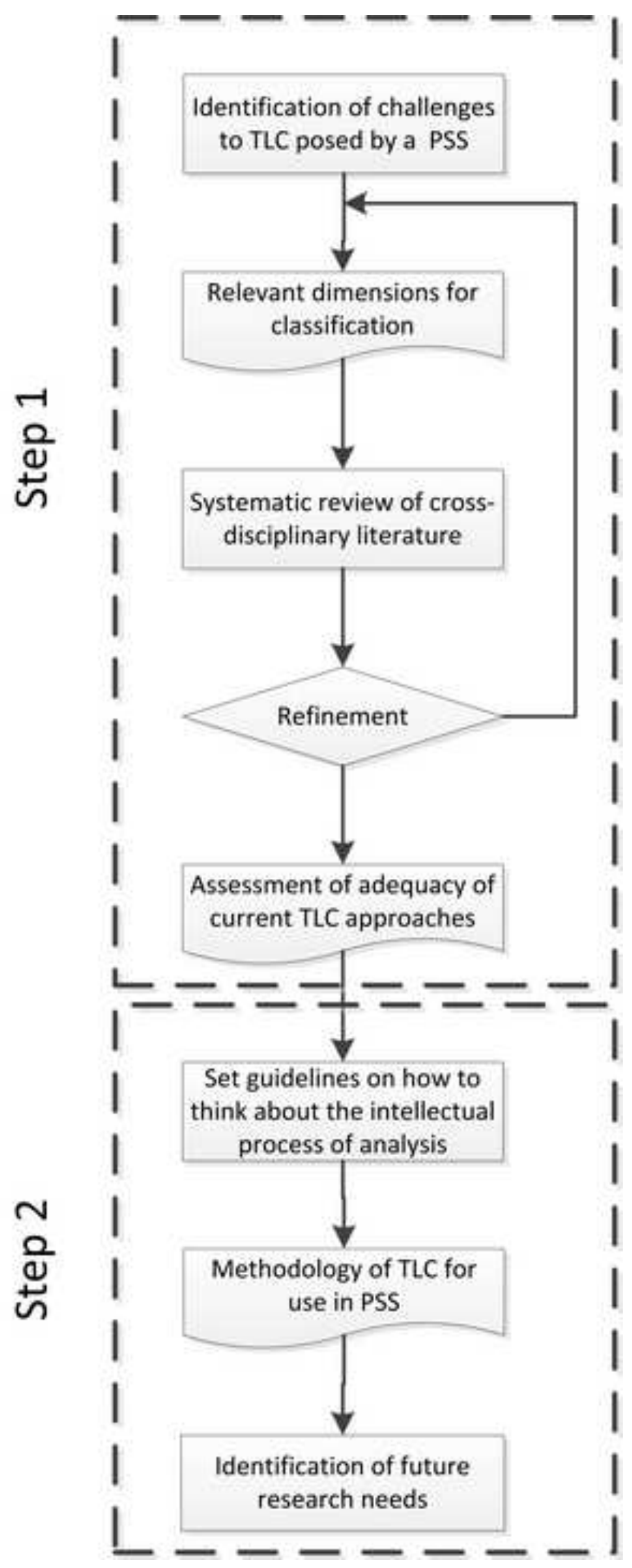


Figure $2 \mathrm{~A}$

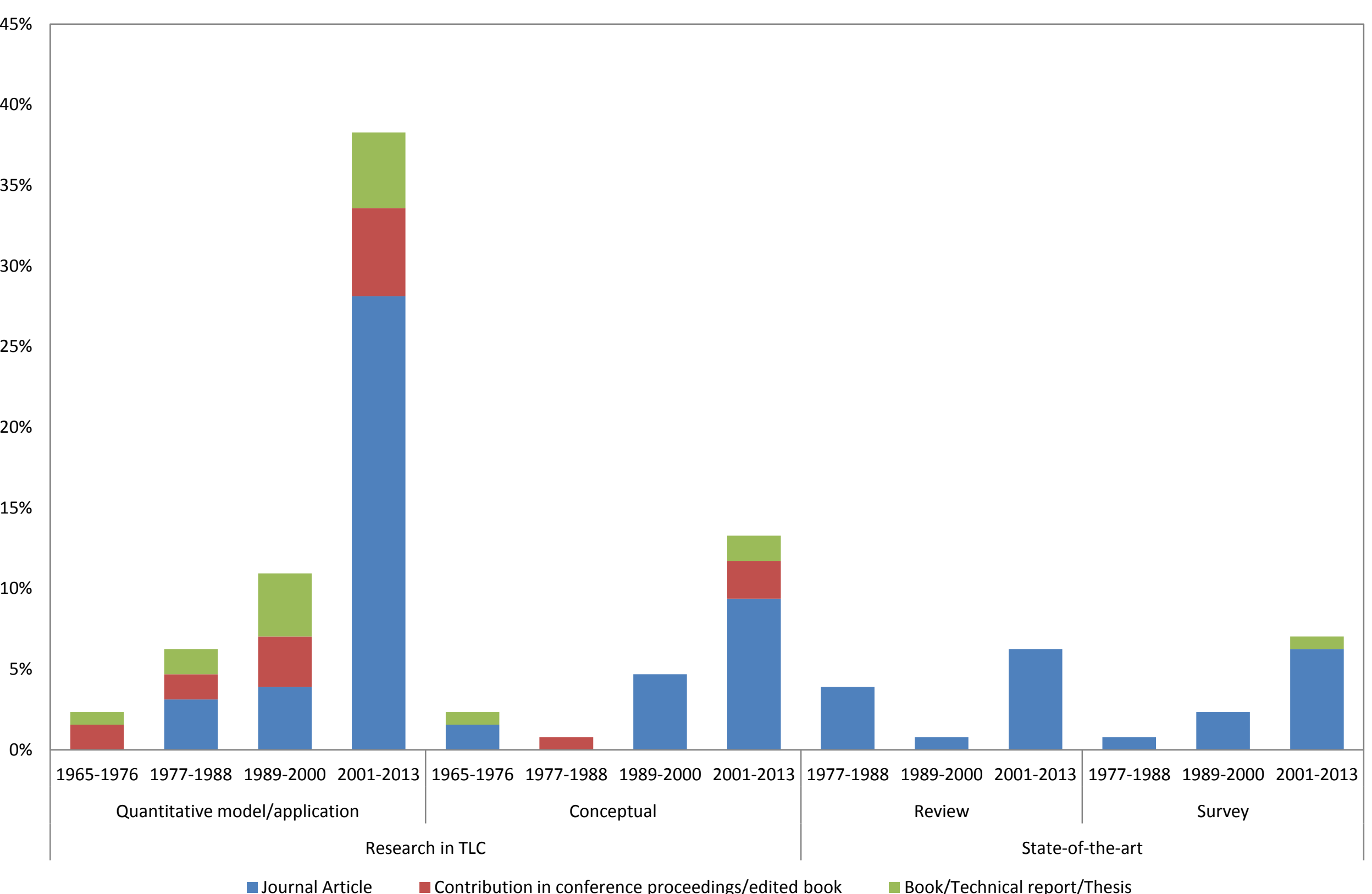

Figure 2A: Overview of reviewed work on TLC by source, type of research and year 


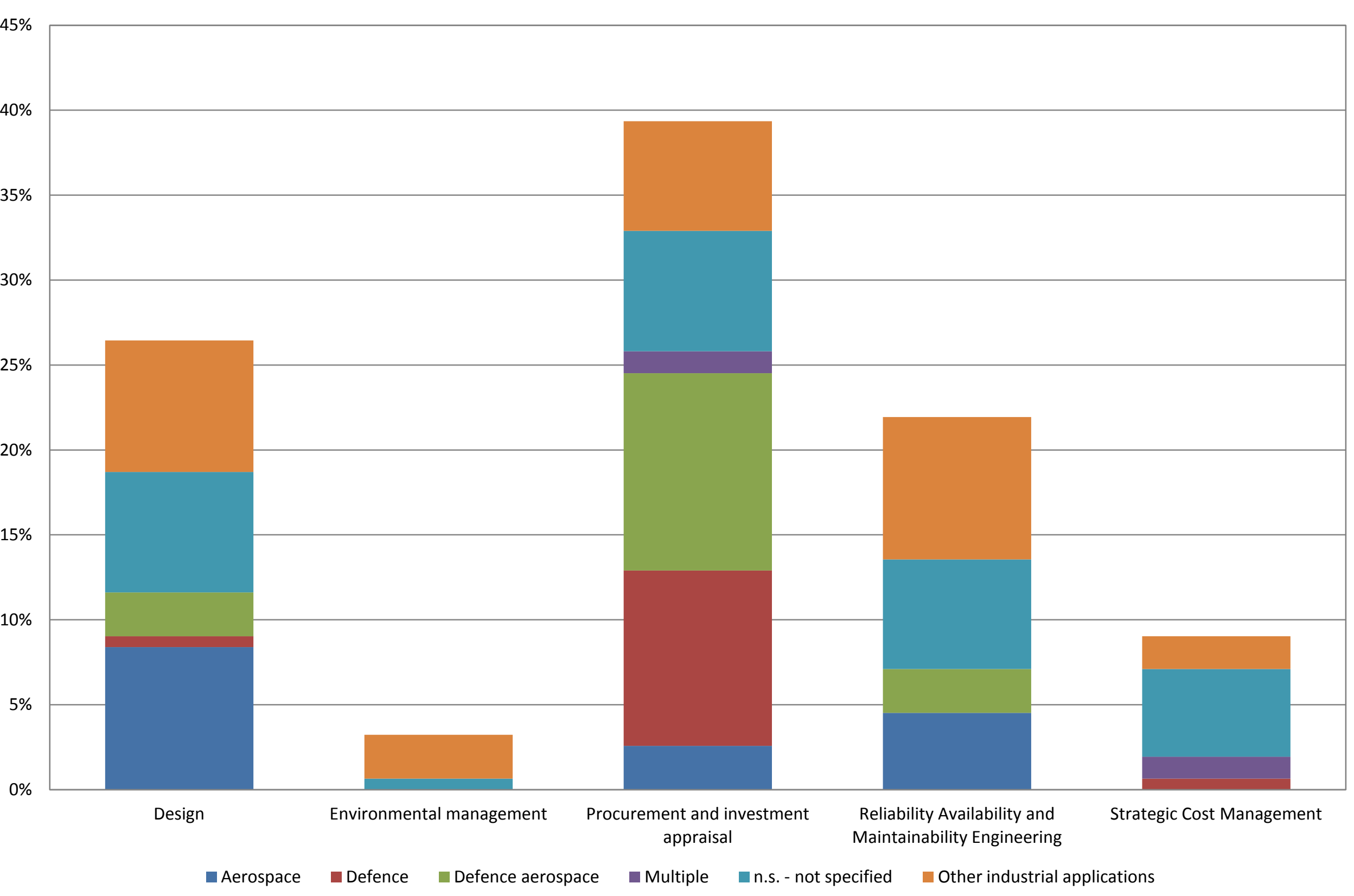

Figure 2B: Overview of reviewed work by discipline and application 


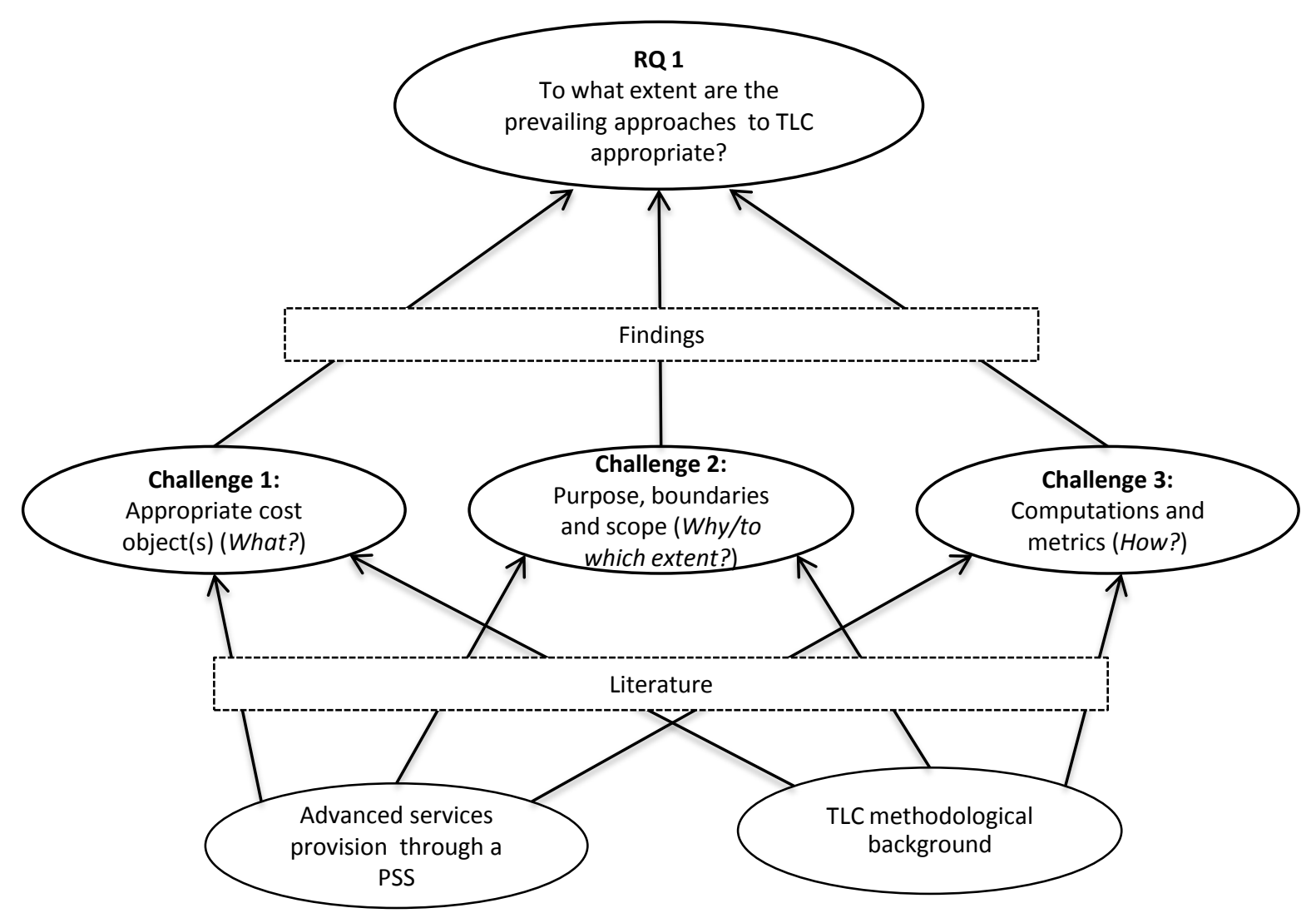

Figure 3: Challenges posed by the concept of PSS to TLC 


\section{Inputs}

- Resources subject to or supporting a transformation, and enabling conditions ;

- Refer directly to a specific level of aggregation

- Acquired outside the process boundaries

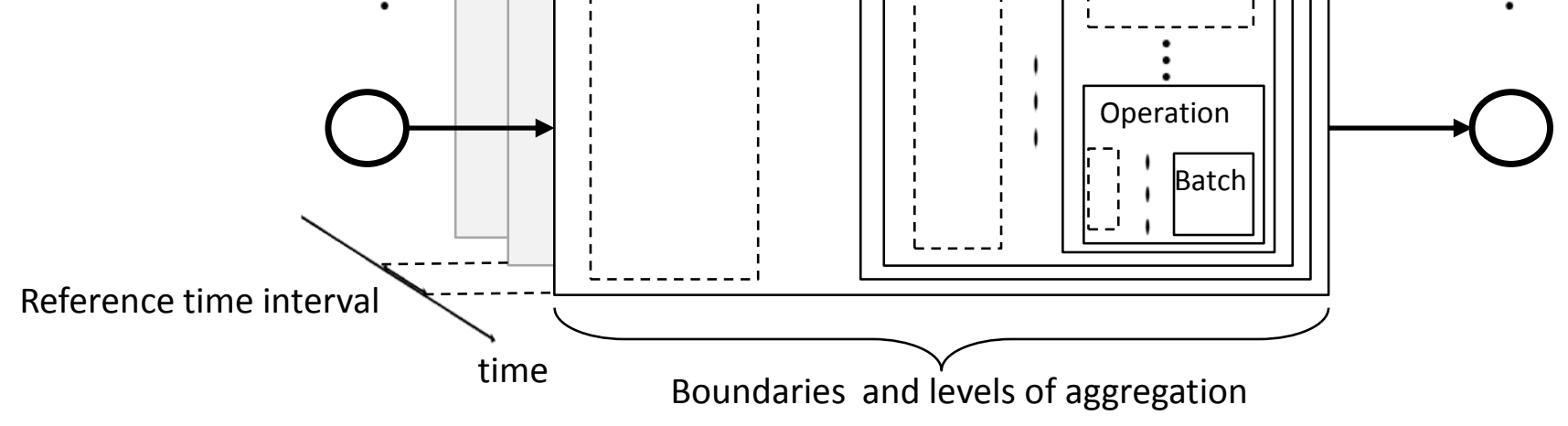

\section{Outputs/outcomes}

- Deliveries (also byproducts and waste)/final achievements, and enabling conditions resulting from a transformation;

- Demanded (or disposed of) outside the process boundaries 


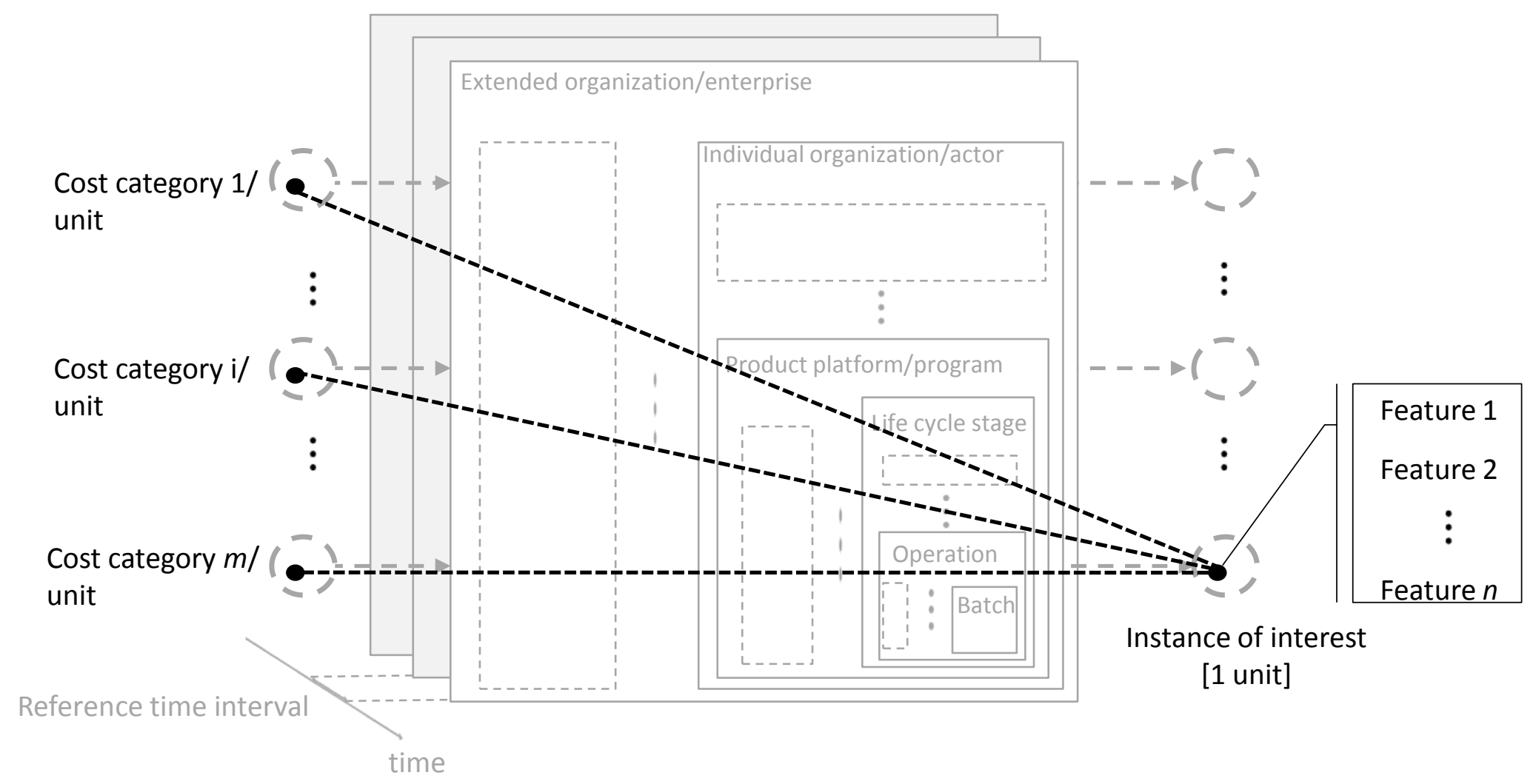

Figure 4B: Reference units for cost assessment: A standalone instance 


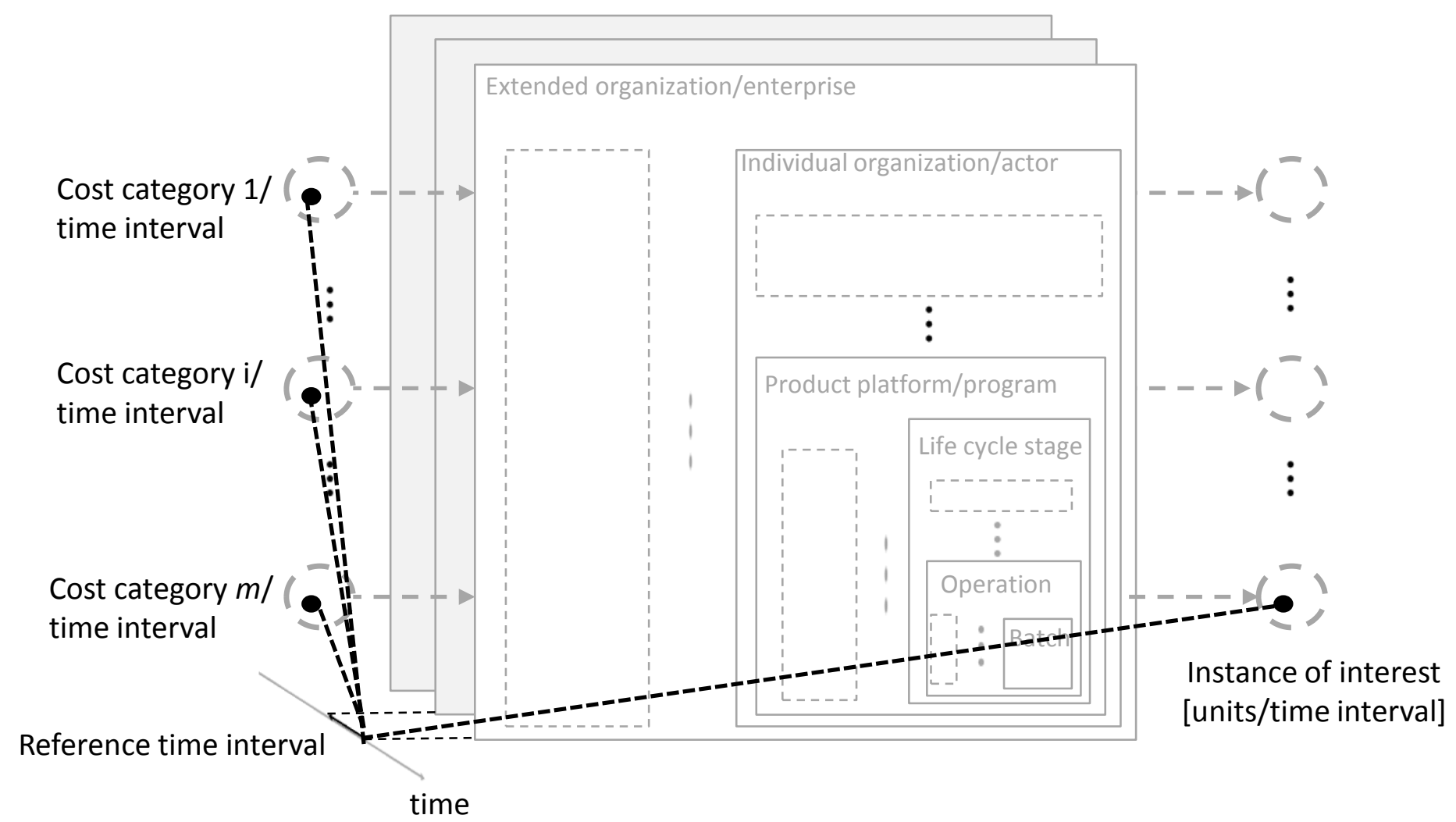

Figure 4C: Reference units for cost assessment: A time interval 


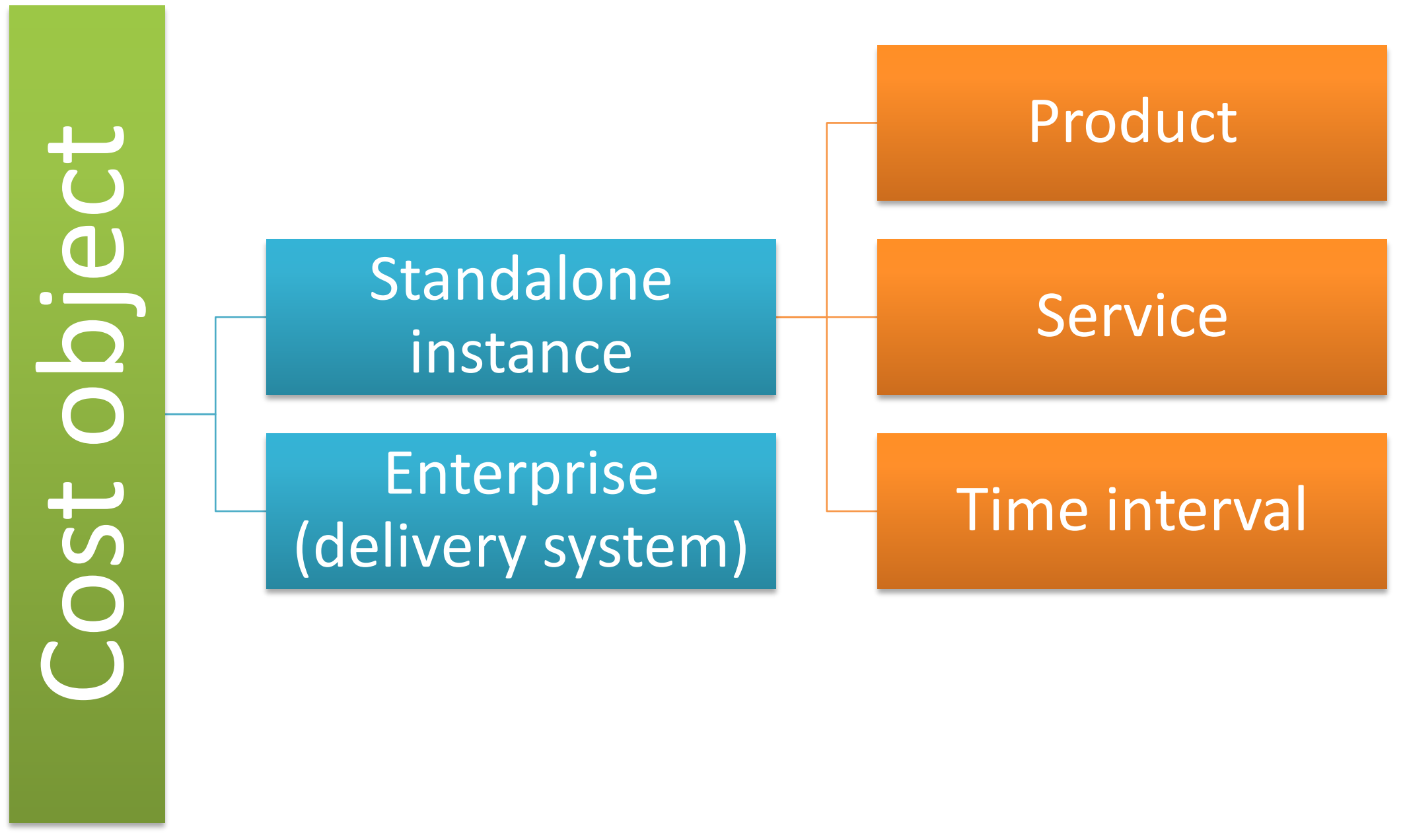

Figure 5: Dimensions for the analysis of TLC literature related to the cost object 


\section{Quantitative research}

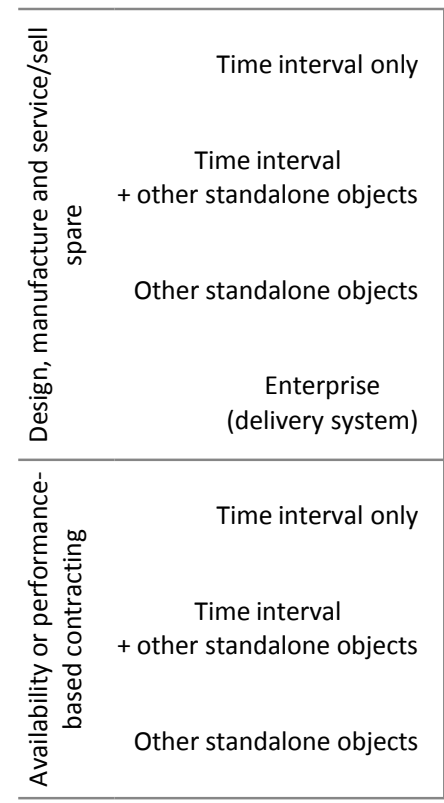

Conceptual research
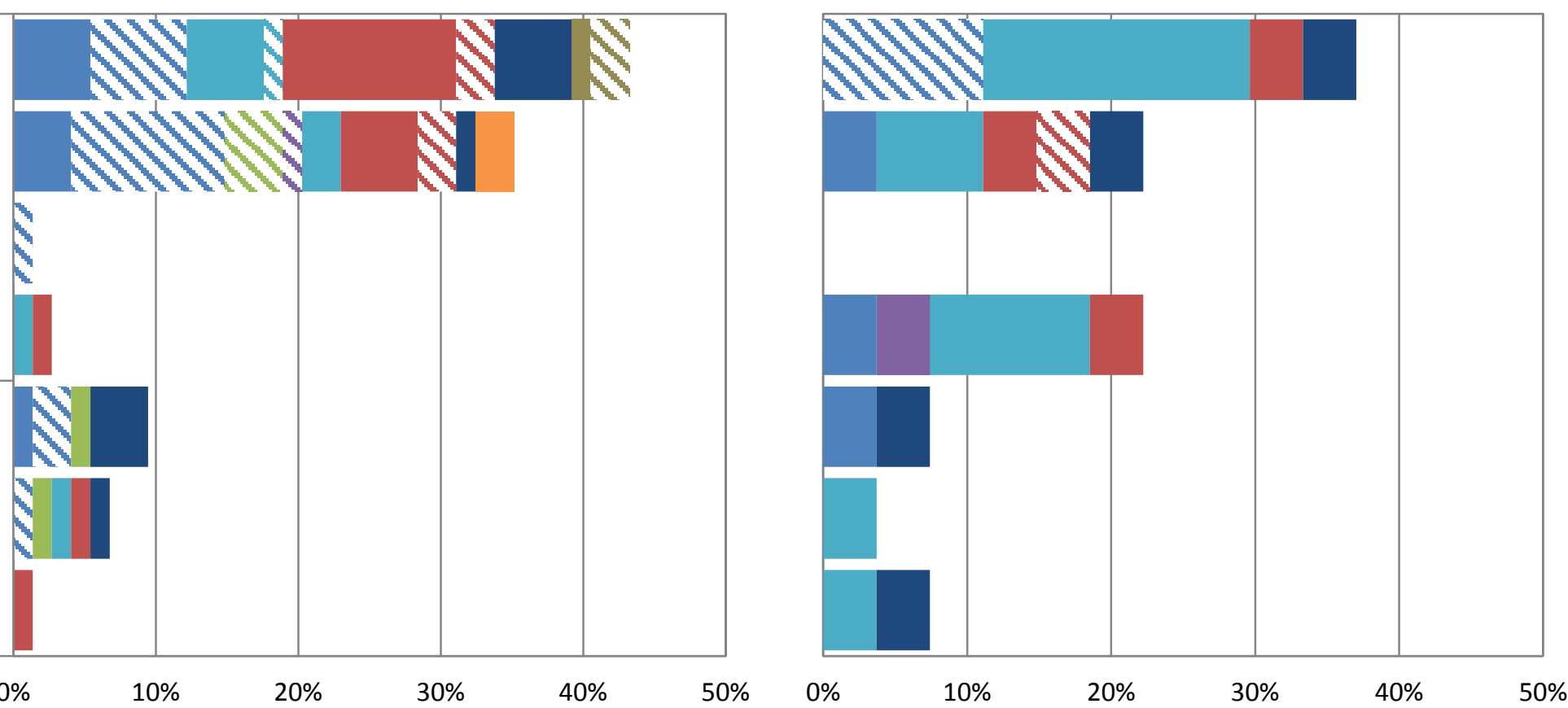

$\begin{array}{ll}\square / C & \text { A/C subsystems - avionics } \\ \square \text { Construction } & \text { Consumer equipment } \\ \square \text { Manufacturing/testing equipment } & \text { Microelectronics } \\ \square \text { n.s - not specified } & \text { Transportation system }\end{array}$

A/C subsystems - engines

General applicability model

- Military equipment
A/C subsystems - other

Human Resource

Multiple 
Figure 7: Recurring cost objects in TLC

Click here to download high resolution image

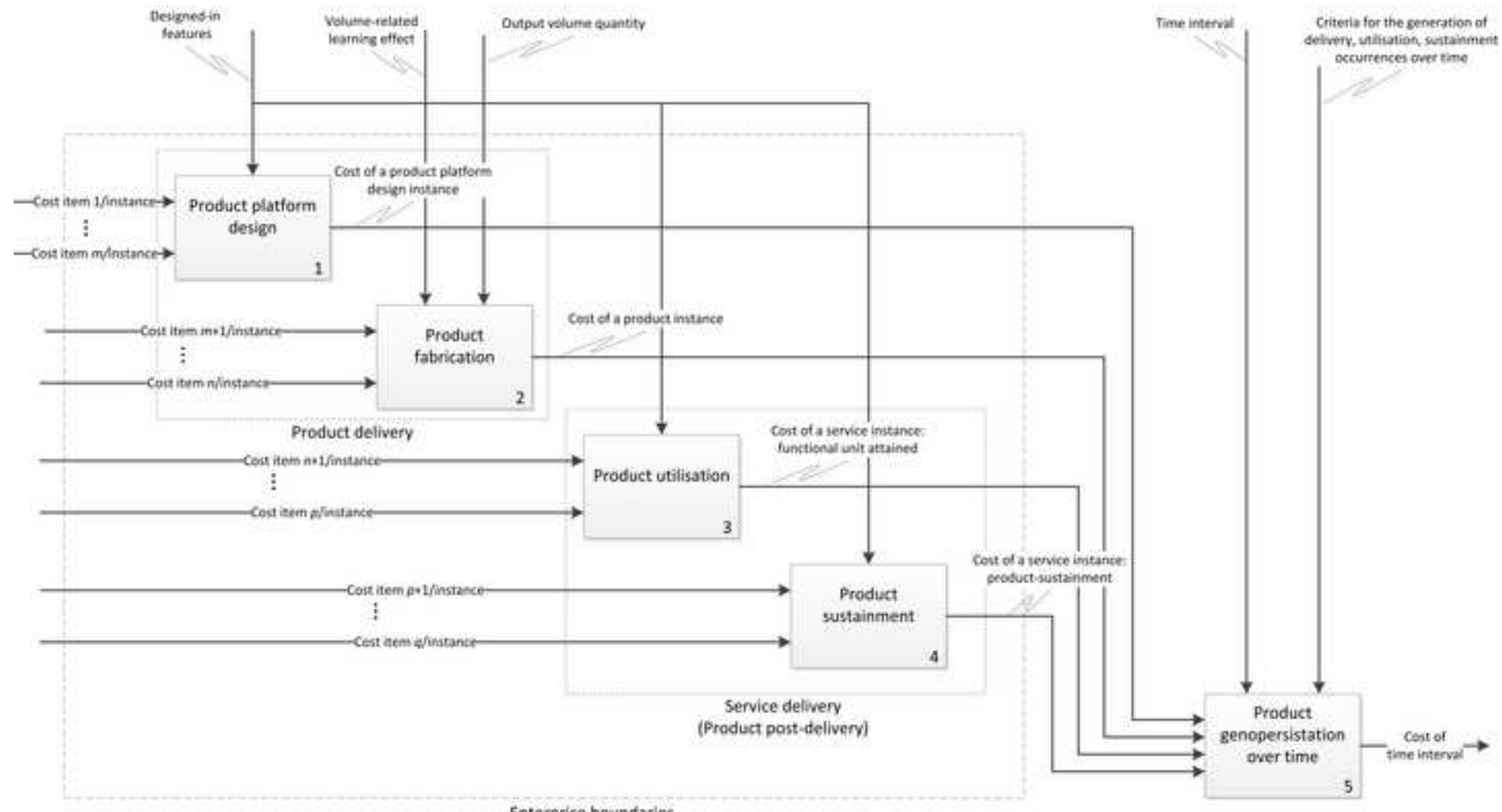




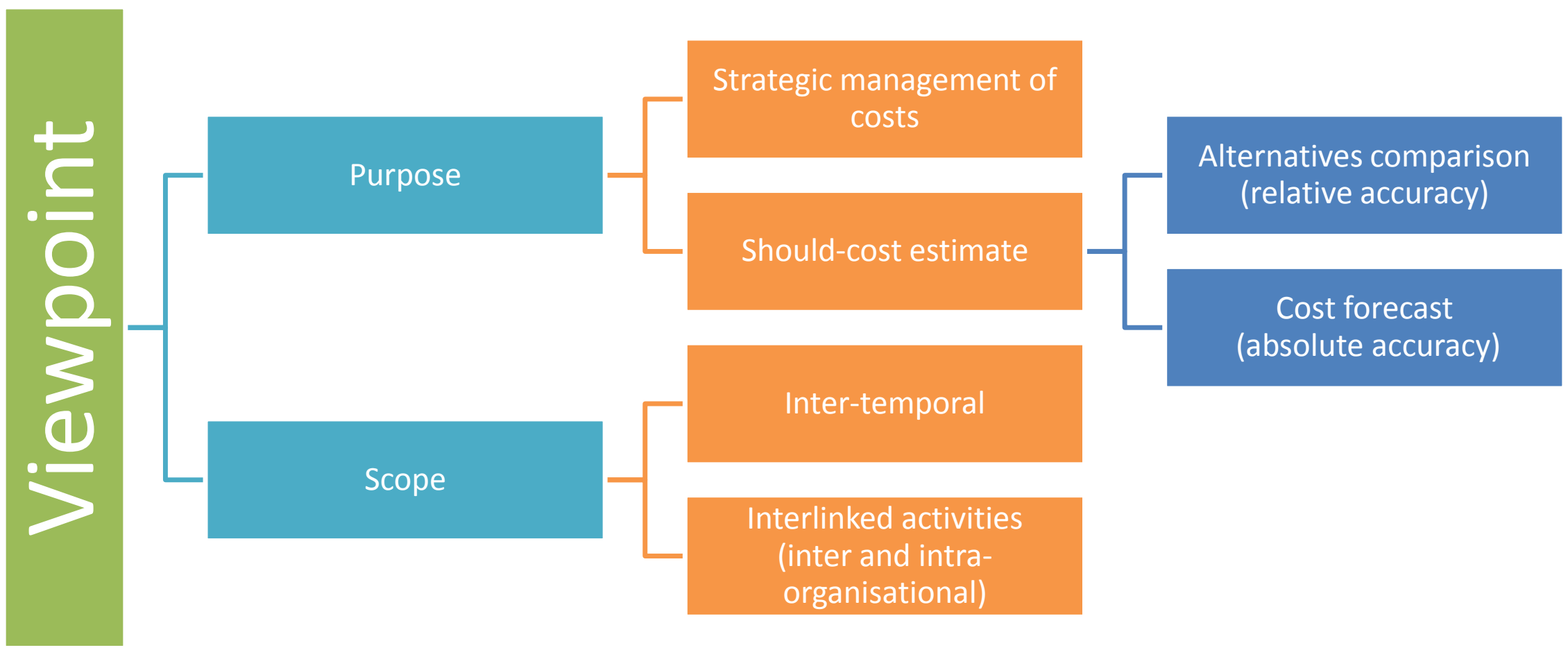

Figure 8: Dimensions for the analysis related to the viewpoint challenge 


\section{Quantitative research}

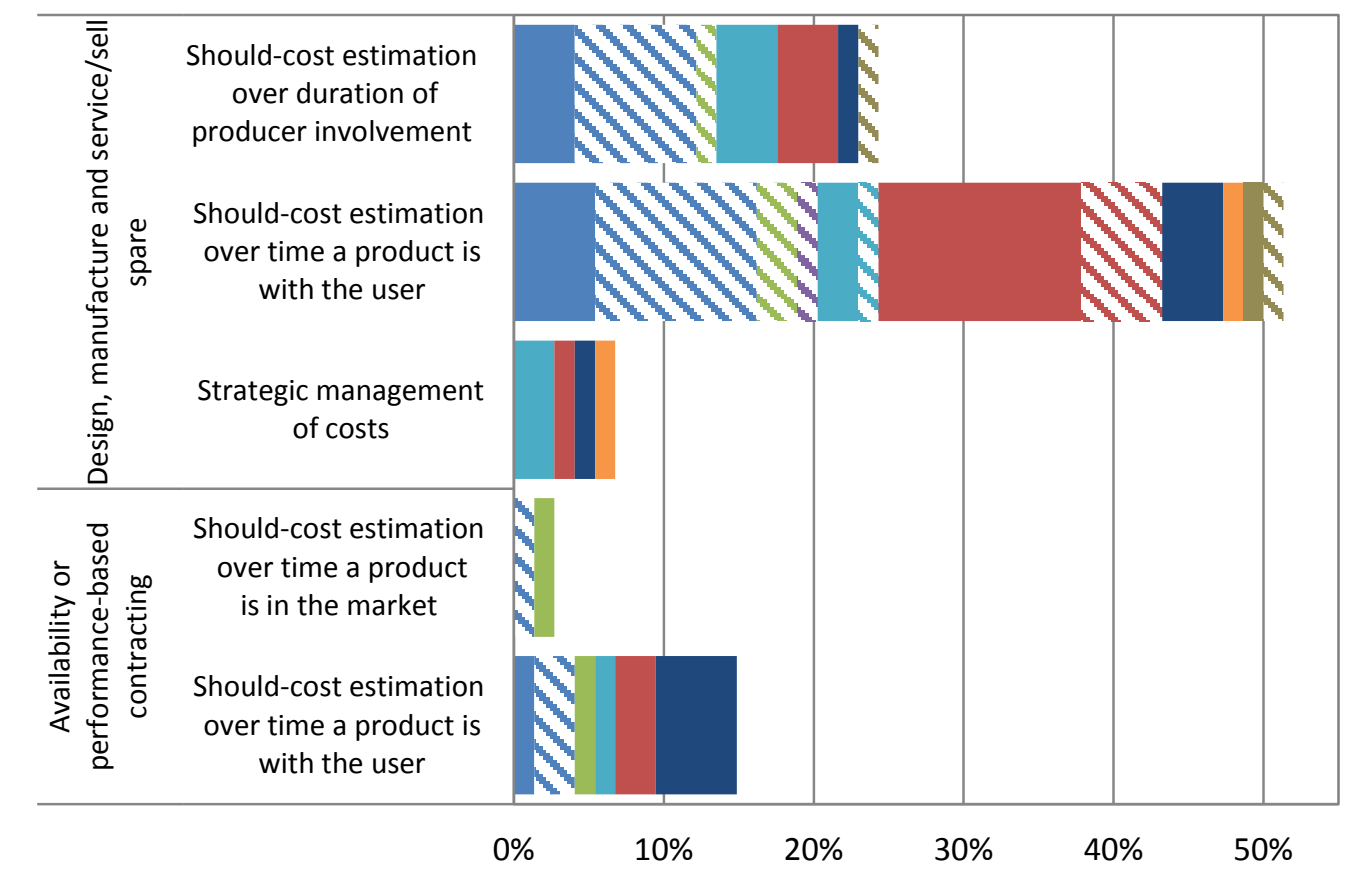

Conceptual research

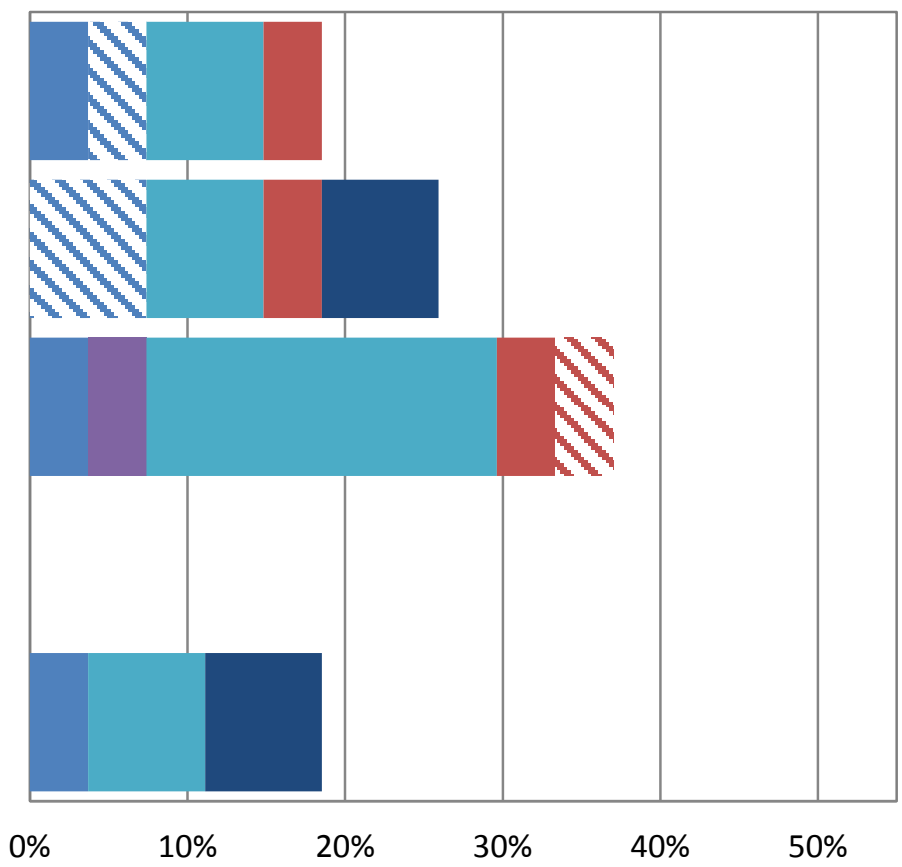

$\begin{array}{ll}\square \text { A/C } & \text { A/C subsystems - avionics } \\ \square \text { Construction } & \text { Consumer equipment } \\ \square \text { Manufacturing/testing equipment } & \text { Microelectronics } \\ \square \text { n.s - not specified } & \text { Transportation system }\end{array}$

A/C subsystems - engines

- General applicability model

Military equipment
A/C subsystems - other
Human Resource
Multiple 


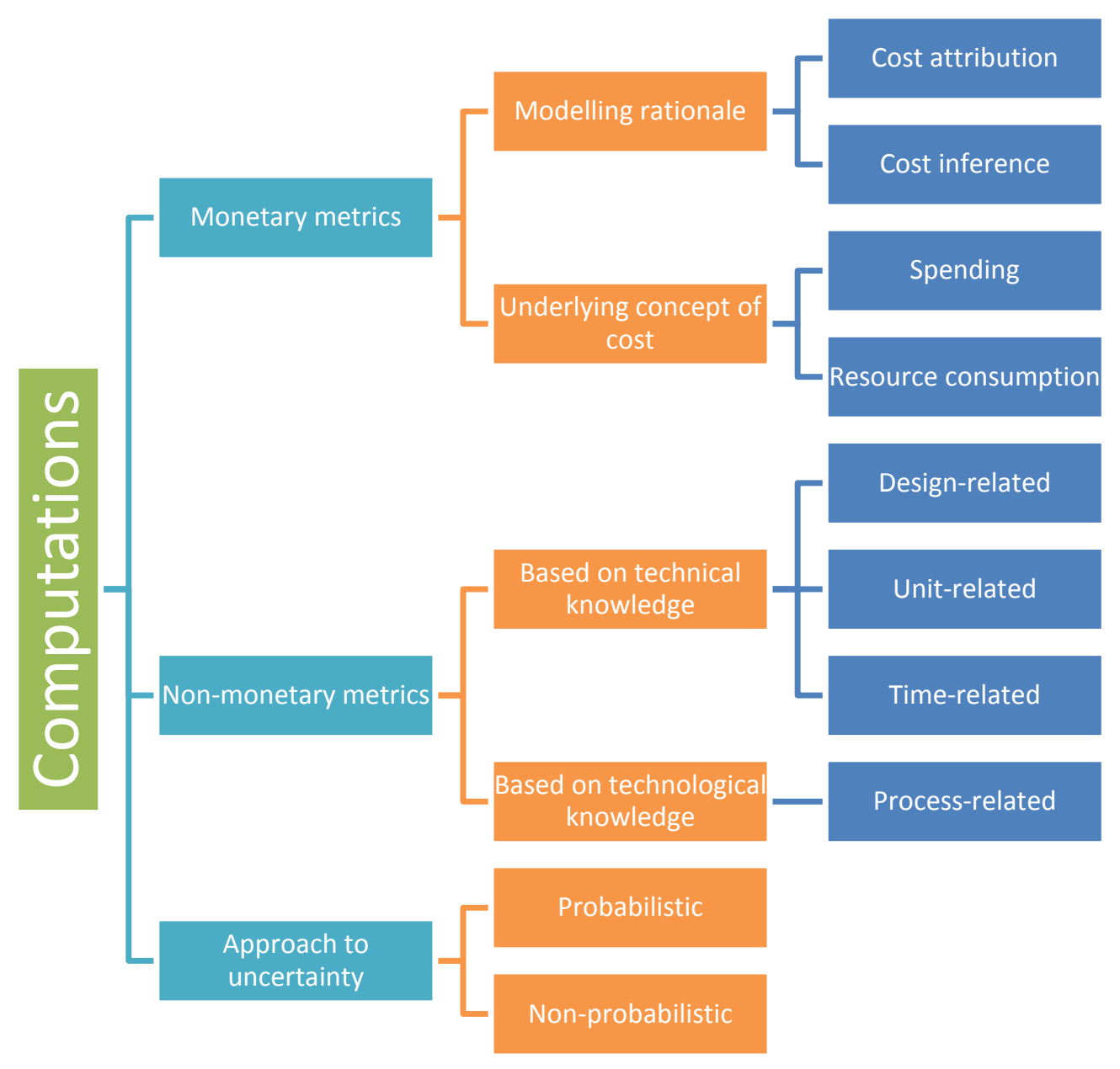

Figure 10: Dimensions for the analysis related to the computations challenge 
Figure 11: computational approaches to cost assessment

Click here to download high resolution image

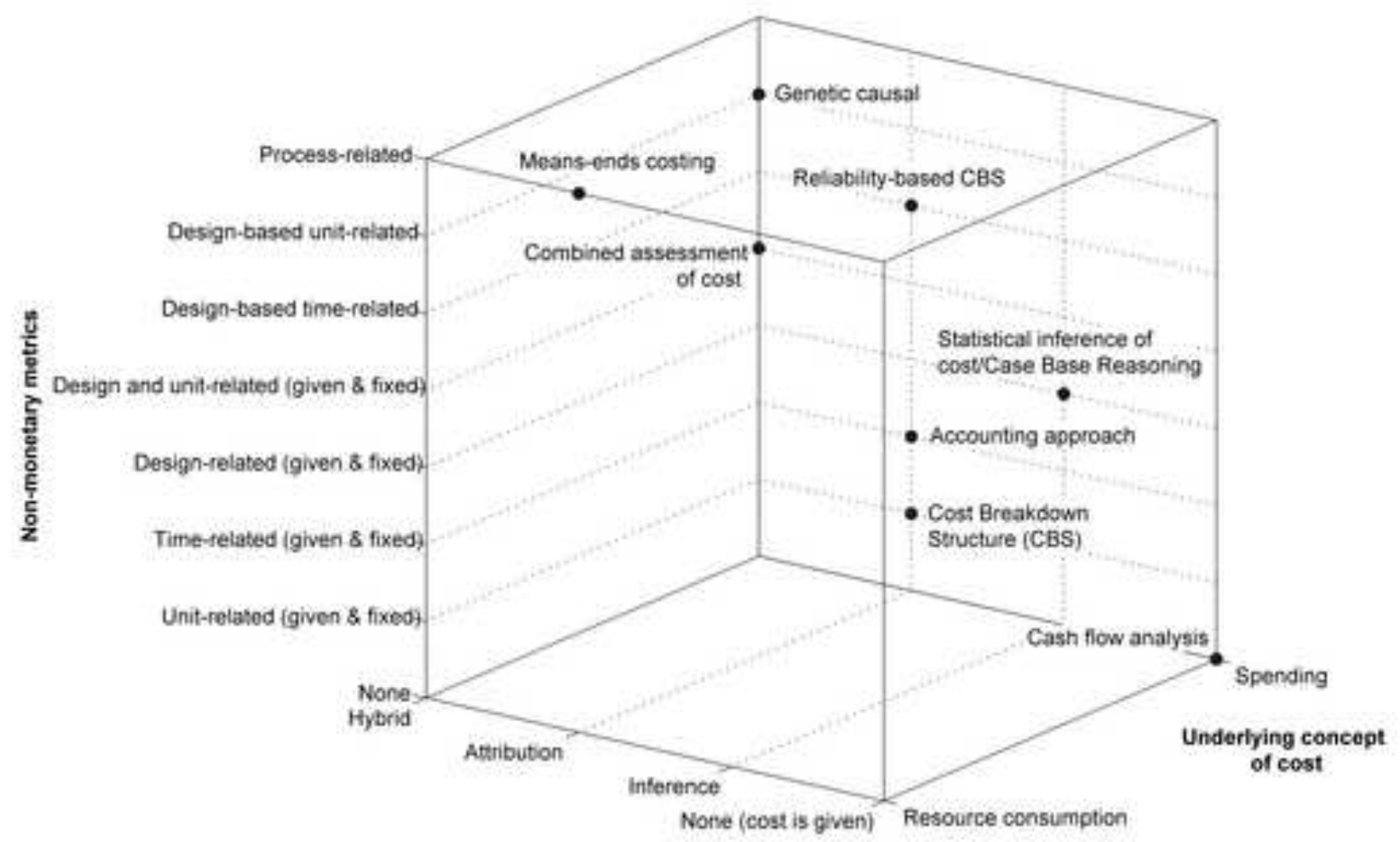

Cost modoling rationale 


\section{Quantitative research}

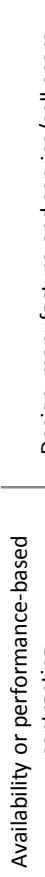
objects' cost

CF only

Combined CBS, SI/CBR of standalone objects' cost Means-ends costing Other

REL and combined CBS, SI/CBR of product and/or service's cost

$\mathrm{SI} / \mathrm{CBR}$ of standalone objects' cost CBS of standalon objects' cost CF only Combined CBS, SI/CBR of standalone objects' cost Other

REL and combined CBS, SI/CBR of product and/or service's cost

REL only

$\mathrm{SI} / \mathrm{CBR}$ of standalone
CBS of standalone

REL only objects' cost

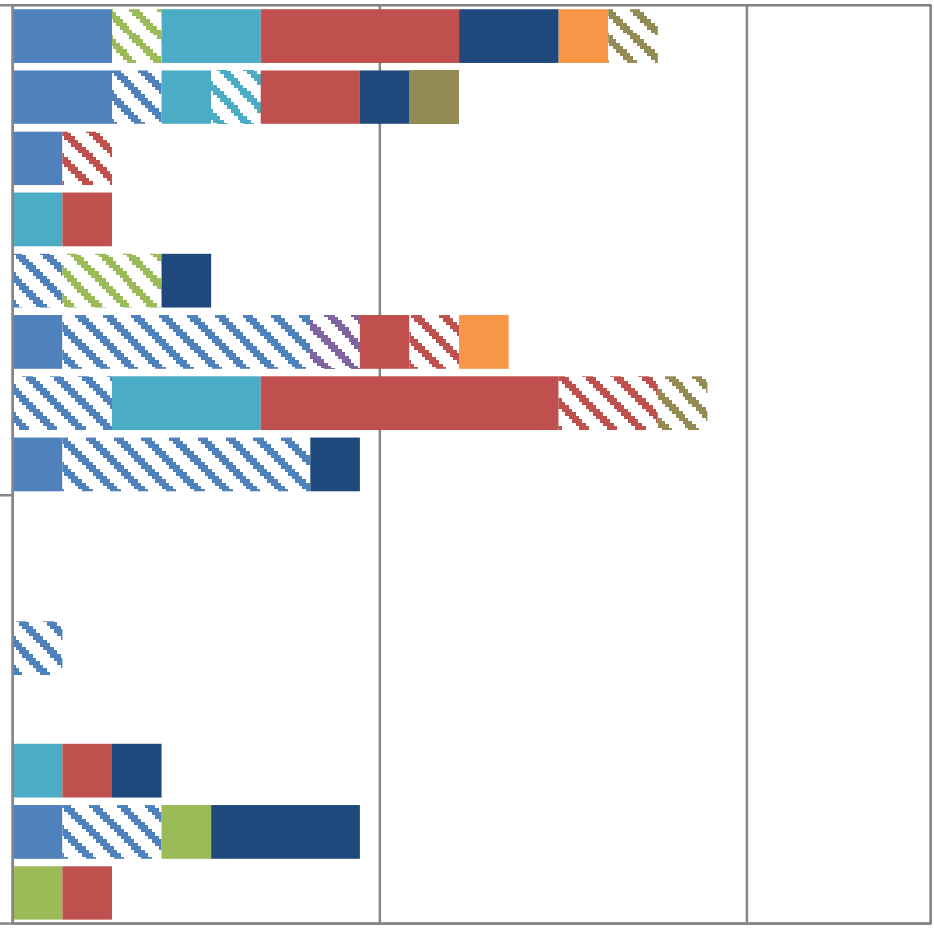

$0 \%$
Conceptual research

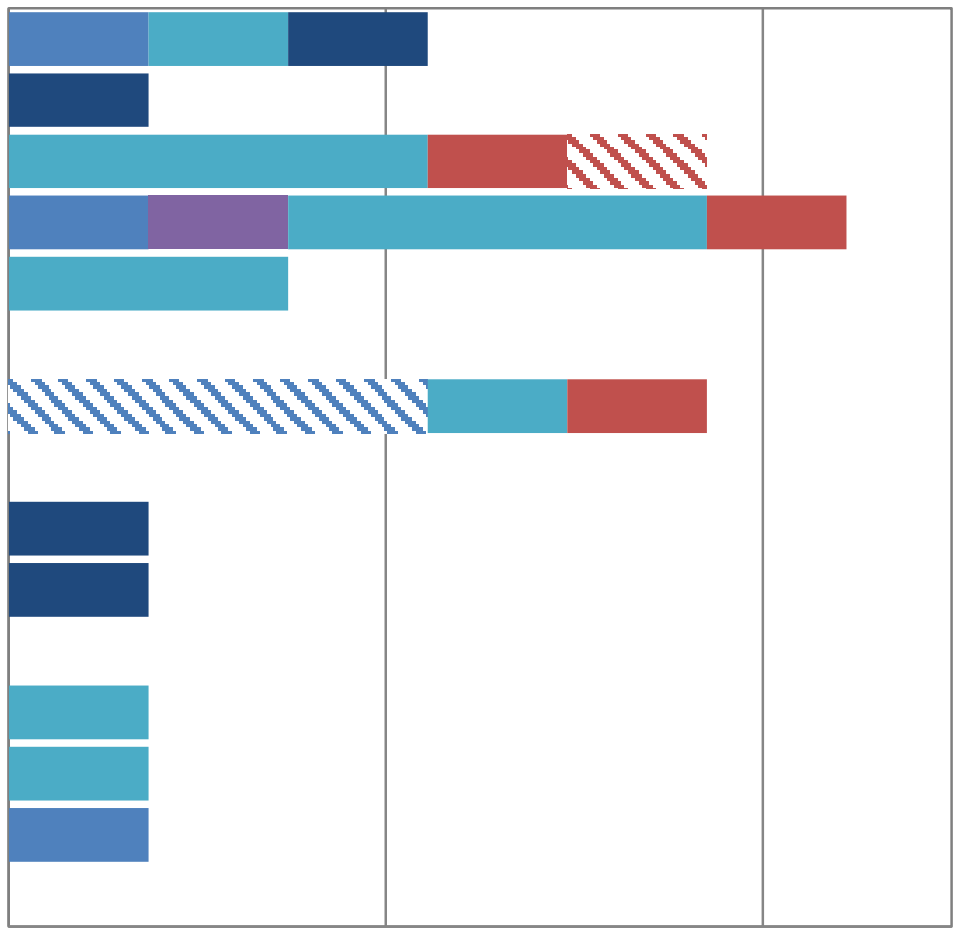

$0 \%$

$10 \%$

$20 \%$

Abbreviations: $\mathrm{CBS}=$ Cost breakdown structure; Gen = Genetic causal approach; $\mathrm{AA}=$ Accounting approach; REL = Reliability-based $\mathrm{CBS} ; \mathrm{SI} / \mathrm{CBR}=\mathrm{Statistical}$ cost inference $/$ CaseBased Reasoning ; $C A=$ Combined assessment; $C F=$ Cash flow analysis. See Table 4 for descriptions.
$\square \mathrm{A} / \mathrm{C}$
A/C subsystems - avionics
A/C subsystems - engines
A/C subsystems - other
Construction
Consumer equipment
- General applicability model
Human Resource
Manufacturing/testing equipment
Microelectronics
Military equipment
Multiple
n.s - not specified
Transportation system 


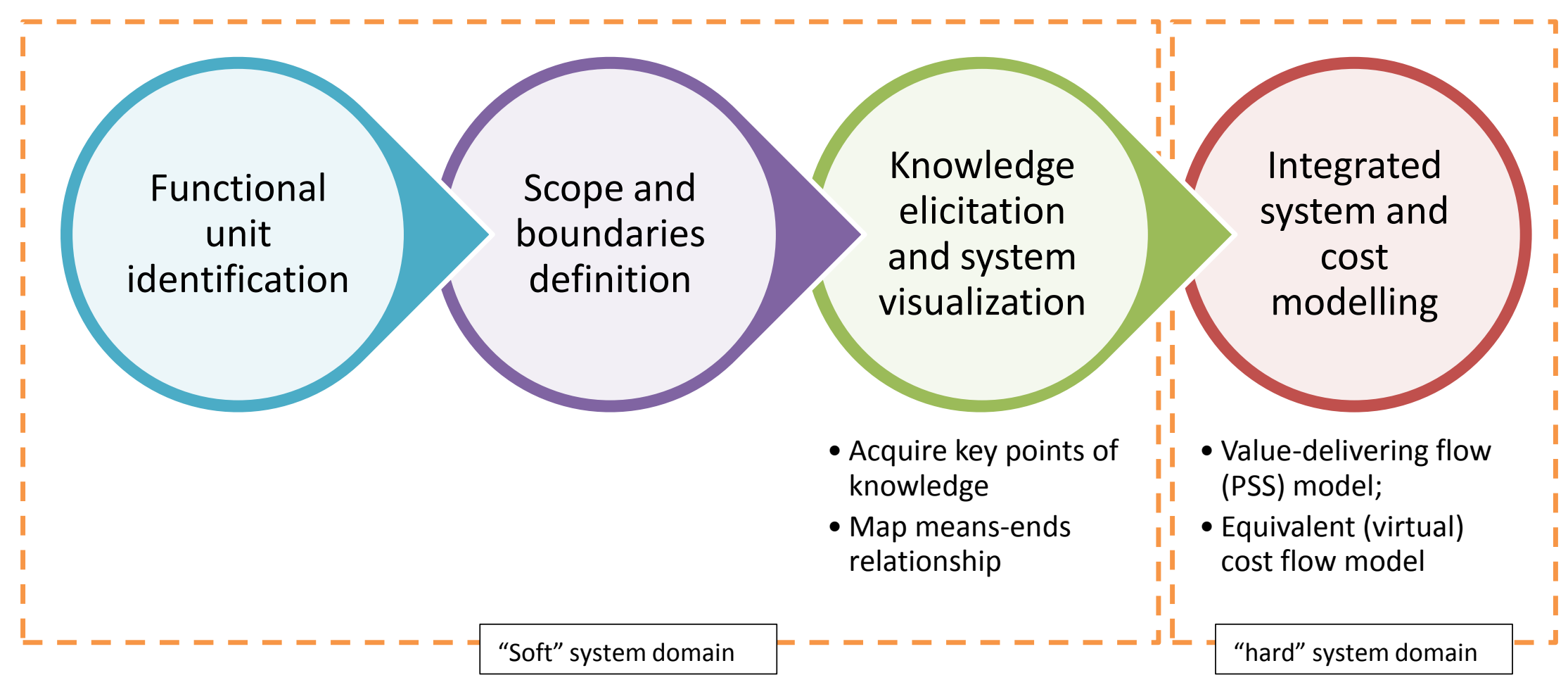

Figure 13: Proposed methodology of TLC for advanced services delivered through a PSS 
Table 1 Diffusion and implementation of TLC

\begin{tabular}{|c|c|c|c|c|c|c|c|c|c|}
\hline \multirow[t]{2}{*}{ Reference } & \multicolumn{5}{|c|}{ Areas covered } & \multicolumn{4}{|c|}{ Method(s) } \\
\hline & $\begin{array}{c}\text { Concept } \\
\text { investigated }\end{array}$ & $\begin{array}{l}\text { Issues with } \\
\text { concept and } \\
\text { technique }\end{array}$ & $\begin{array}{c}\text { Issues with } \\
\text { implementation in } \\
\text { industry }\end{array}$ & Sector(s) & Geographic area & Survey & Literature & Delphi & $\begin{array}{l}\text { Action } \\
\text { research }\end{array}$ \\
\hline Assaf et al. (2002) & LCC & $\bullet$ & $\bullet$ & Construction & Saudi Arabia & $\bullet$ & $\bullet$ & & \\
\hline Cinquini and Tenucci (2010) & $\begin{array}{l}\text { LCC (not } \\
\text { exclusively) }\end{array}$ & & $\bullet$ & Manufacturing & Italy & $\bullet$ & & & \\
\hline Dunk (2004) & LCC & & $\bullet$ & Manufacturing & Australia & $\bullet$ & $\bullet$ & & \\
\hline Ellram (1995) & $\mathrm{TCO}$ & $\bullet$ & $\bullet$ & $\begin{array}{l}\text { electronics, and defence } \\
\text { aviation) }\end{array}$ & not specified & $\bullet$ & $\bullet$ & & \\
\hline Ferrin and Plank (2002) & TCO & & $\bullet$ & $\begin{array}{l}\text { Manufacturing; Service; } \\
\text { Government }\end{array}$ & United States & $\bullet$ & & & \\
\hline Jackson and Ostrom (1980) & LCC & & $\bullet$ & not specified & United States & $\bullet$ & & & \\
\hline James (2003) & $\begin{array}{l}\text { LCC } \\
\text { (Environmental) }\end{array}$ & $\bullet$ & $\bullet$ & Food packaging & Australia & $\bullet$ & & & \\
\hline Lindholm and Suomala (2002) & LCC & $\bullet$ & $\bullet$ & not specified & Finland & & $\bullet$ & & \\
\hline Nicolini et al. (2000) & $\begin{array}{l}\text { WLC (not } \\
\text { exclusively) }\end{array}$ & & $\bullet$ & $\begin{array}{l}\text { Defence and } \\
\text { Construction }\end{array}$ & United Kingdom & & & & $\bullet$ \\
\hline Olubodun et al. (2010) & LCC & & $\bullet$ & Construction & United Kingdom & $\bullet$ & & & \\
\hline Shields and Young (1991) & LCC & & $\bullet$ & $\begin{array}{l}\text { Aerospace and } \\
\text { electronics }\end{array}$ & $\begin{array}{l}\text { United States and } \\
\text { Europe }\end{array}$ & - & $\bullet$ & & \\
\hline Tysseland (2008) & $\mathrm{LCC}$ & & $\bullet$ & Defence & Norway & $\bullet$ & & & \\
\hline Xu et al. (2012) & $\begin{array}{l}\text { LCC (not } \\
\text { exclusively) }\end{array}$ & $\bullet$ & & not specified & United Kingdom & & $\bullet$ & - & \\
\hline
\end{tabular}




\begin{tabular}{|c|c|c|c|c|c|c|c|c|c|c|}
\hline & \multicolumn{4}{|c|}{ General contribution } & \multicolumn{6}{|c|}{ Domain-specific contribution } \\
\hline & 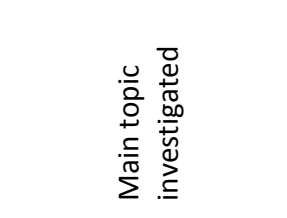 & 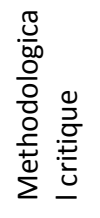 & 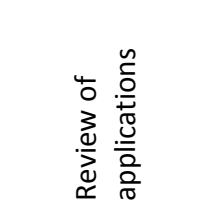 & 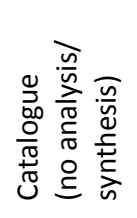 & 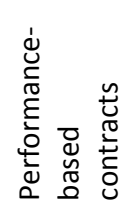 & 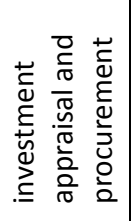 & 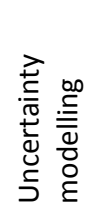 & 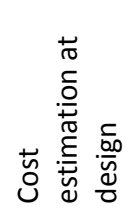 & 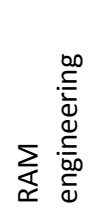 & 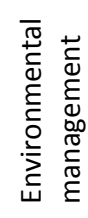 \\
\hline \multicolumn{11}{|l|}{ Reviews of literature } \\
\hline Asiedu and Gu (1998) & LCC, CET & $\bullet$ & & & & & & $\bullet$ & & \\
\hline Christensen et al. (2005) & LCC & $\bullet$ & & & & & $\bullet$ & - & & \\
\hline Dhillon (1981) & LCC & & & $\bullet$ & & & & & $\bullet$ & \\
\hline Durairaj et al. (2002) & LCC & $\bullet$ & & & & & & & & $\bullet$ \\
\hline Erkoyuncu et al. $(2011 b)^{a}$ & CET & $\bullet$ & & & $\bullet$ & $\bullet$ & $\bullet$ & & & \\
\hline Geissdörfer et al. (2009) & LCC & & & & & $\bullet$ & & & & \\
\hline Goh et al. (2010) & LCC & $\bullet$ & & & & & $\bullet$ & $\bullet$ & & \\
\hline Gupta and Chow (1985) & LCC & & & $\bullet$ & & & & & $\bullet$ & \\
\hline Kaenzig and Wüstenhagen (2010) & LCC & & - $\quad$ Multiple & & & & & & & $\bullet$ \\
\hline Keller et al. (2014) & CET & $\bullet$ & - $\quad$ Aerospace & & & $\bullet$ & & & & \\
\hline Korpi and Ala-Risku (2008) & LCC & & - Multiple & & & $\bullet$ & & $\bullet$ & & \\
\hline Ntuen and Moore (1986) & LCC & $\bullet$ & & & & & & & - & \\
\hline Sherif and Kheir (1982) & LCC & & - Defence & & & & & & $\bullet$ & \\
\hline Sherif and Kolarik (1981) & LCC & $\bullet$ & - Multiple & & & & & & - & \\
\hline \multicolumn{11}{|l|}{ Research works with extensive literature review ${ }^{b}$} \\
\hline Cheung et al. (2009) & CET & & & & & & & $\bullet$ & & \\
\hline Curran et al. (2004) & CET, LCC & $\bullet$ & - Aerospace & & & & & $\bullet$ & & \\
\hline Datta and Roy (2010) & CET & $\bullet$ & & & - & & & & & \\
\hline Dhillon (2010) & LCC & & - Multiple & $\bullet$ & & & & & $\bullet$ & \\
\hline Hunkeler et al. (2008) & LCC (environmental) & $\bullet$ & - Multiple & & & & & & & $\bullet$ \\
\hline Settanni et al. (2011) & LCC & $\bullet$ & & & & & & & & $\bullet$ \\
\hline Waghmode and Sahasrabudhe (2011) & LCC & & & & & & & & $\bullet$ & \\
\hline
\end{tabular}

${ }^{a}$ Refers to TLC indirectly as the cost of the in-service stage of a product.

${ }^{\mathrm{b}}$ Also included in other tables.

$\mathrm{CET}=$ Cost Estimating Techniques 
Table 3 Concepts of life cycle and repercussion on TLC scope and purpose

\begin{tabular}{|c|c|c|c|c|c|}
\hline \multirow{2}{*}{\multicolumn{2}{|c|}{ Nature of the life cycle }} & \multirow[t]{2}{*}{ Standpoint } & \multicolumn{2}{|c|}{ TLC scope } & \multirow[t]{2}{*}{ TLC purpose } \\
\hline & & & Temporal sequence & Physical sequence & \\
\hline \multirow[t]{4}{*}{$\begin{array}{l}\text { Inter- } \\
\text { temporal }\end{array}$} & $\begin{array}{l}\text { Time-span a product unit is with the } \\
\text { customer (consumable life) }\end{array}$ & Customer's & $\begin{array}{l}\text { Acquisition } \\
\text { Use } \\
\text { Sustainment } \\
\text { End-of-life treatment }\end{array}$ & N/A & $\begin{array}{l}\text { Expand the owner's cost analysis } \\
\text { over time, beyond the moment a } \\
\text { durable good is purchased. }\end{array}$ \\
\hline & $\begin{array}{l}\text { Duration of the producer's involvement over } \\
\text { a single product unit (consumable life) }\end{array}$ & Overlapping customer-provider's & $\begin{array}{l}\text { Use } \\
\text { Sustainment } \\
\text { End-of-life treatment }\end{array}$ & N/A & $\begin{array}{l}\text { Expand the producer's cost } \\
\text { analysis beyond the moment a } \\
\text { product unit is sold. }\end{array}$ \\
\hline & $\begin{array}{l}\text { Duration of the producer's involvement over } \\
\text { a product platform (revenue-generating life) }\end{array}$ & Provider's & $\begin{array}{l}\text { Design (conceptual to detailed) } \\
\text { Sustain } \\
\text { Manufacture } \\
\text { Retire/dispose of }\end{array}$ & N/A & $\begin{array}{l}\text { Expand the producer's cost } \\
\text { analysis over time, for the } \\
\text { duration of its involvement with } \\
\text { a product unit. }\end{array}$ \\
\hline & $\begin{array}{l}\text { Time-span a product platform (or family, } \\
\text { brand) is in the market }\end{array}$ & Marketing's & $\begin{array}{l}\text { Introduction } \\
\text { Growth } \\
\text { Maturity } \\
\text { Decline }\end{array}$ & N/A & $\begin{array}{l}\text { Monitor and manage costs and } \\
\text { profitability as they evolve while } \\
\text { a product platform or product } \\
\text { family is in the market }\end{array}$ \\
\hline $\begin{array}{l}\text { Interlinked } \\
\text { activities }\end{array}$ & $\begin{array}{l}\text { Linear chain of physically linked steps related } \\
\text { to a single product unit without any temporal } \\
\text { specification }\end{array}$ & $\begin{array}{l}\text { Value chain's } \\
\text { (product's, if organisation-neutral) }\end{array}$ & $\mathrm{N} / \mathrm{A}$ & $\begin{array}{l}\text { Raw materials extraction } \\
\text { Intermediate goods production } \\
\text { Final goods production } \\
\text { Logistics and distribution } \\
\text { Utilisation } \\
\text { Sustainment } \\
\text { End-of-life treatment }\end{array}$ & $\begin{array}{l}\text { Extend cost dimension beyond } \\
\text { the individual organization } \\
\text { through the physical and } \\
\text { information flows concerning a } \\
\text { product, as defined by inter- } \\
\text { organisational relationships. The } \\
\text { product perspective is } \\
\text { independent from specific } \\
\text { economic actors and the } \\
\text { relationships between them. }\end{array}$ \\
\hline
\end{tabular}

Derived from literature (Emblemsvåg, 2003; Hansen and Mowen, 2003; Hunkeler et al., 2008; Seuring and Goldbach, 2002). “N/A”: not applicable. 
Table 4 Computational orientation in TLC

\begin{tabular}{|c|c|}
\hline $\begin{array}{l}\text { Computational } \\
\text { approach }\end{array}$ & Description \\
\hline $\begin{array}{l}\text { Cost breakdown } \\
\text { structure (CBS) }\end{array}$ & $\begin{array}{l}\text { Hierarchical decomposition of the direct unit cost of any of the cost objects identified in Figure 7, } \\
\text { developed through unit-related metrics which are fixed and given (e.g., Hunkeler et al., 2008). }\end{array}$ \\
\hline $\begin{array}{l}\text { Genetic causal } \\
\text { approach (Gen) }\end{array}$ & $\begin{array}{l}\text { Like a CBS, it is based on a cost attribution rationale. However, the unit-related metrics are } \\
\text { expressed analytically as a function of design-related metrics, for example based on principles of } \\
\text { statistical inference (Curran et al., 2004). }\end{array}$ \\
\hline $\begin{array}{l}\text { Accounting approach } \\
\text { (AA) }\end{array}$ & $\begin{array}{l}\text { An instance of time is related with both input and output quantities through time-related non- } \\
\text { monetary metrics that are fixed and given. Output quantities typically serve as an allocation base } \\
\text { (e.g., Hitt, 1997). }\end{array}$ \\
\hline $\begin{array}{c}\text { Reliability-based CBS } \\
\text { (REL-CBS) }\end{array}$ & $\begin{array}{l}\text { Establishes correspondence between an instance of time and time-related metrics such as the } \\
\text { occurrences of product-sustaining events. These metrics are expressed analytically as a function } \\
\text { of logistic variables (failure rates, Mean Time Between Failures etc.) which are specific to a } \\
\text { product design (e.g., Sandborn, 2013). }\end{array}$ \\
\hline $\begin{array}{l}\text { Statistical cost } \\
\text { inference (SI)/ } \\
\text { Case-Based Reasoning } \\
\text { (CBR) }\end{array}$ & $\begin{array}{l}\text { Although the specific techniques vary, a cost object's cost is estimated comparatively according } \\
\text { to the similarity and differentiation of a number of like cases for which the same cost is known } \\
\text { (see for example Kilpatrick and Jones, 1974). In Case Base Reasoning (CBR) the cost figure of } \\
\text { interest is obtained by adjusting an existing case's known cost (e.g., Romero Rojo et al., 2012). }\end{array}$ \\
\hline Means-ends costing & $\begin{array}{l}\text { Combines a notion of cost as resource consumption orientation with a cost attribution rationale } \\
\text { and process metrics. Handles multiple types of product and service simultaneously. Examples } \\
\text { include Activity Based Life Cycle Costing (AB-LCC) (Emblemsvåg, 2003), and Input-Output Life } \\
\text { Cycle Costing (Settanni and Emblemsvåg, 2010). }\end{array}$ \\
\hline $\begin{array}{l}\text { Combined assessment } \\
\text { (CA) }\end{array}$ & $\begin{array}{l}\text { Simultaneously employ more of the above, for example a cost breakdown structure and } \\
\text { statistical cost inference (e.g., Cheung et al., 2009) }\end{array}$ \\
\hline Cash flow analysis (CF) & $\begin{array}{l}\text { The relevant monetary metrics are movements of cash or cash equivalents either given or } \\
\text { derived directly with reference to a specific time-span (e.g., } f / y e a r, k W h / y e a r \times f / k W h \text { etc.). } \\
\text { Aggregation over time typically involves discounting (Hansen and Mowen, 2003). }\end{array}$ \\
\hline
\end{tabular}


Table 5 Summary of challenges, findings and gaps

\begin{tabular}{|c|c|c|c|}
\hline Challenges & $\begin{array}{c}\text { Propositions about costing advanced services } \\
\text { provided through a PSS }\end{array}$ & Findings about TLC methodological background & Potential gaps \\
\hline $\begin{array}{l}\text { Challenge 1: What is the appropriate cost } \\
\text { object when costing an advanced service } \\
\text { delivered by a PSS? }\end{array}$ & $\begin{array}{l}\text { Proposition 1: A reductionist approach that } \\
\text { focuses on one cost object at a time is not } \\
\text { appropriate for a PSS. A PSS is a system } \\
\text { potentially involving multiple, interconnected } \\
\text { and interacting cost objects simultaneously. }\end{array}$ & $\begin{array}{l}\text { Finding 1: TLC deals with one cost object at a } \\
\text { time, be it an instance of product, service or } \\
\text { time. The cost of a PSS tends to be identified } \\
\text { with the expenditures accumulating over the } \\
\text { time-span a stand-alone asset is in-service. }\end{array}$ & $\begin{array}{l}\text { Gap 1: TLC is not methodologically } \\
\text { equipped to deal with a system, specifically } \\
\text { socio-technical systems. }\end{array}$ \\
\hline $\begin{array}{l}\text { Challenge 2: What is the purpose of } \\
\text { costing an advanced service delivered by } \\
\text { a PSS? What are the scope and } \\
\text { boundaries of the analysis? }\end{array}$ & $\begin{array}{l}\text { Proposition 2: If the purpose of a PSS is to } \\
\text { exploit strategic alliances on a continuous } \\
\text { basis its scope should cover interlinked } \\
\text { activities performed within and across the } \\
\text { organisational boundaries. Its scope } \\
\text { should be also inter-temporal, since the } \\
\text { impact of decisions on the state of the PSS } \\
\text { at subsequent times has to be considered. }\end{array}$ & $\begin{array}{l}\text { Finding 2: TLC is a one-off, should-cost } \\
\text { estimation exercise undertaken by the buying } \\
\text { or the selling organisation independently. Its } \\
\text { scope tends to be determined as the time-span } \\
\text { a product exists, rather than the actions } \\
\text { performed, their outcomes, relationships and } \\
\text { occurrence. }\end{array}$ & $\begin{array}{l}\text { Gap 2: TLC cannot support cost } \\
\text { consciousness which requires continuous } \\
\text { monitoring of how cost and performance } \\
\text { evolve as a course of action is undertaken, } \\
\text { within and across the relevant } \\
\text { organisational boundaries. }\end{array}$ \\
\hline $\begin{array}{l}\text { Challenge 3: What are the computational } \\
\text { aspects of costing an advanced service } \\
\text { delivered through a PSS? What are the } \\
\text { metrics involved? }\end{array}$ & $\begin{array}{l}\text { Proposition 3: Costing an advanced service } \\
\text { delivered through a PSS is a problem of } \\
\text { attributing the value of means to the } \\
\text { economic activities carried out for the ends } \\
\text { to be achieved. Cost results from the } \\
\text { interplay between monetary and non- } \\
\text { monetary metrics, and uncertainties } \\
\text { thereof. }\end{array}$ & $\begin{array}{l}\text { Finding 3: Current approaches to TLC directly } \\
\text { and immediately assign a measure of spending } \\
\text { to an individual instance of product, service or } \\
\text { time through non-monetary metrics expressing } \\
\text { technical knowledge about the product. } \\
\text { Uncertainty is addressed in terms of time } \\
\text { distributions describing how an asset operates, } \\
\text { fails and is restored to operation. }\end{array}$ & $\begin{array}{l}\text { Gap 3: TLC per se does not allow answering } \\
\text { the question which costs are to be } \\
\text { attributed to which activity. Rather, the } \\
\text { application of such models as availability- } \\
\text { based TLC requires that the question has } \\
\text { been already answered in such a way that } \\
\text { the model can be entirely expressed in } \\
\text { terms of technical knowledge about an } \\
\text { individual product. }\end{array}$ \\
\hline
\end{tabular}


Table A.1 Conceptual research on TLC - Availability/Performance-based business model. (Abbreviations: see Table 4).

\begin{tabular}{|c|c|c|c|c|c|c|c|c|c|c|c|c|c|c|c|c|c|c|c|c|c|c|c|c|c|c|c|c|c|c|c|c|c|}
\hline \multirow[b]{4}{*}{ References } & \multirow{2}{*}{\multicolumn{5}{|c|}{ Cost object }} & \multicolumn{7}{|c|}{ Viewpoint } & \multicolumn{21}{|c|}{ Computations } \\
\hline & & & & & & \multirow{2}{*}{\multicolumn{2}{|c|}{ Purpose }} & \multirow{2}{*}{\multicolumn{5}{|c|}{ Scope }} & \multirow[b]{3}{*}{ 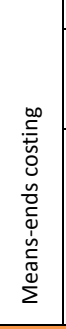 } & \multirow{2}{*}{\multicolumn{7}{|c|}{ Time span }} & & Stand-a & Ione $\mathrm{i}$ & stance & costin & & & & & & & & \\
\hline & \multirow[b]{2}{*}{ 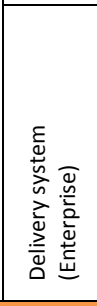 } & \multicolumn{4}{|c|}{ Stand-alone instance } & & & Inter-temporal & & & & $\begin{array}{c}\begin{array}{c}\text { Interlinked } \\
\text { activities }\end{array} \\
\end{array}$ & & & & & & & & & \multicolumn{8}{|c|}{ Product } & \multicolumn{5}{|c|}{$\begin{array}{c}\text { Service } \\
\text { Product-support }\end{array}$} \\
\hline & & 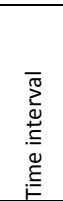 & 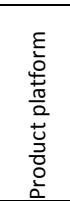 & $\begin{array}{l}\text { 䓂 } \\
\text { 喜 } \\
\text { 홈 }\end{array}$ & 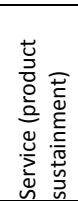 & 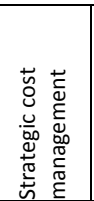 & 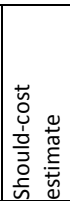 & 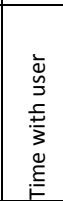 & 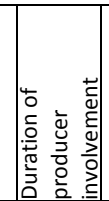 & 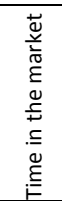 & 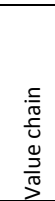 & 总 & & 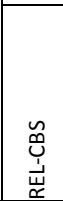 & $\tilde{\mathscr{Q}}$ & $\varangle$ & $\bar{n}$ & 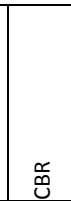 & u & 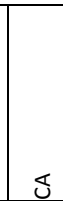 & & 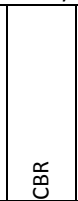 & $\tilde{\mathscr{u}}$ & 芭 & Ј్ & & 営 & $\mathbb{s}$ & $\tilde{O}$ & 矛 & & 受 & 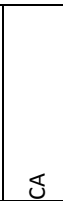 \\
\hline \multicolumn{34}{|l|}{ Aircraft } \\
\hline Buderath (2011) & & - & & & & & - & - & & & & & & - & & & & & & & & & & & & & & & & & & & \\
\hline \multicolumn{34}{|l|}{ General applicability } \\
\hline Huang et al. (2012) & & . & & & - & & - & - & & & & & & & & & & & & & & & & & & & & & & & & & - \\
\hline Roy and Erkoyuncu (2011) & & - & & & $\bullet$ & & $\bullet$ & $\bullet$ & & & & & & - & & & & & & & & & & & & & & & & & & & $\bullet$ \\
\hline \multicolumn{34}{|l|}{ Military equipment } \\
\hline Bankole et al. (2012) & & - & & & & & - & - & & & & & & & & & & & - & & & & & & & & & & & & & & \\
\hline Datta and Roy (2010) & & & & & - & & - & - & & & & & & & & & & & & & & & & & & & & & - & & & & \\
\hline
\end{tabular}


Table A.2 Conceptual research on TLC - "product and support" business model. (Abbreviations: see Table 4)

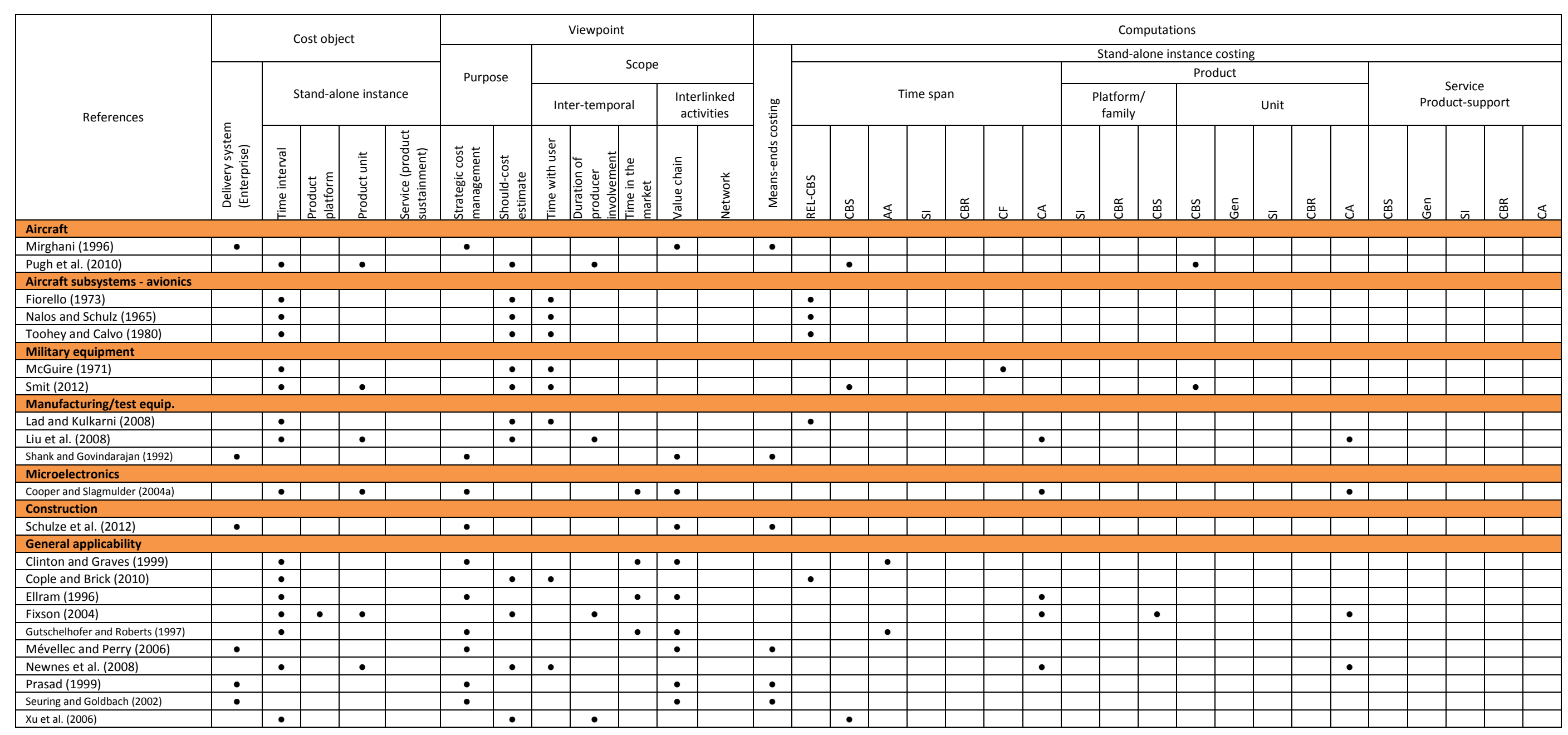


Table A.3 Quantitative research in TLC - Availability/Performance-based business model. (Abbreviations: see Table 4).

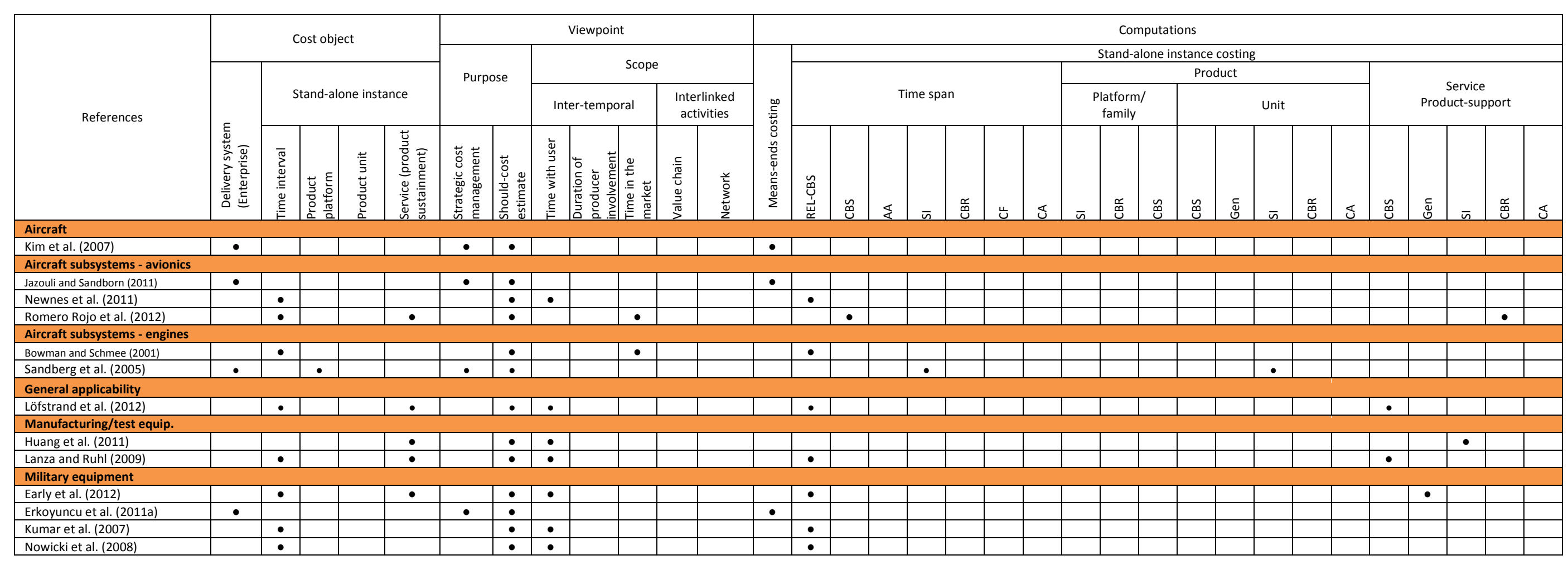


Table A.3 (continued) - Quantitative research in TLC - Availability/Performance-based business model.

\begin{tabular}{|c|c|c|c|c|c|c|c|c|c|c|c|c|c|}
\hline \multirow{4}{*}{ References } & \multicolumn{8}{|c|}{ Non-monetary metrics } & \multicolumn{5}{|c|}{ Uncertainty } \\
\hline & \multicolumn{5}{|c|}{ Primary } & \multicolumn{3}{|c|}{ Derived } & \multirow{3}{*}{ 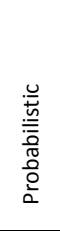 } & \multirow{3}{*}{ 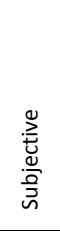 } & \multicolumn{3}{|c|}{ Random event generation } \\
\hline & \multirow{2}{*}{ 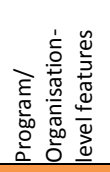 } & \multirow{2}{*}{ 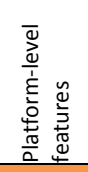 } & \multicolumn{2}{|c|}{ Unit-level metrics } & \multirow{2}{*}{ 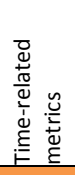 } & \multirow[b]{2}{*}{ 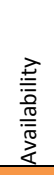 } & \multirow{2}{*}{ 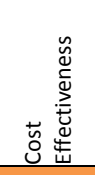 } & \multirow[b]{2}{*}{ 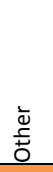 } & & & \multirow[b]{2}{*}{ 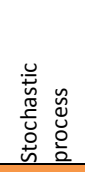 } & \multirow[b]{2}{*}{ 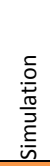 } & \multirow{2}{*}{ 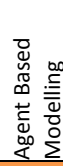 } \\
\hline & & & Product & Service & & & & & & & & & \\
\hline \multicolumn{14}{|l|}{ Aircraft } \\
\hline Kim et al. (2007) & & $\bullet$ & & & $\bullet$ & $\bullet$ & & & $\bullet$ & & & & \\
\hline \multicolumn{14}{|l|}{ Aircraft subsystems - avionics } \\
\hline Jazouli and Sandborn (2011) & & $\bullet$ & & & $\bullet$ & - & & & $\bullet$ & & & $\bullet$ & \\
\hline Newnes et al. (2011) & & & & & $\bullet$ & & & & $\bullet$ & & & & \\
\hline Romero Rojo et al. (2012) & & $\bullet$ & & & $\bullet$ & & & & $\bullet$ & & & & \\
\hline \multicolumn{14}{|l|}{ Aircraft subsystems - engines } \\
\hline Bowman and Schmee (2001) & - & $\bullet$ & & & $\bullet$ & - & & & - & & & - & \\
\hline Sandberg et al. (2005) & & $\bullet$ & & & $\bullet$ & & & & & & & & \\
\hline \multicolumn{14}{|l|}{ General applicability } \\
\hline Löfstrand et al. (2012) & & - & & - & - & & & & - & & & - & \\
\hline \multicolumn{14}{|l|}{ Manufacturing/test equip. } \\
\hline Huang et al. (2011) & & - & & & $\bullet$ & & & & & & & & \\
\hline Lanza and Ruhl (2009) & & $\bullet$ & & & $\bullet$ & & & & $\bullet$ & & & - & \\
\hline \multicolumn{14}{|l|}{ Military equipment } \\
\hline Early et al. (2012) & & $\bullet$ & & & $\bullet$ & & & & $\bullet$ & & $\bullet$ & & \\
\hline Erkoyuncu et al. (2011a) & & $\bullet$ & & & $\bullet$ & & & & & - & & & $\bullet$ \\
\hline Kumar et al. (2007) & & $\bullet$ & & & $\bullet$ & $\bullet$ & & & $\bullet$ & & $\bullet$ & & \\
\hline Nowicki et al. (2008) & & $\bullet$ & & & $\bullet$ & $\bullet$ & & & $\bullet$ & & $\bullet$ & & \\
\hline
\end{tabular}


Table A.4 Quantitative research in TLC - "product and support" business model. (Abbreviations: see Table 4)

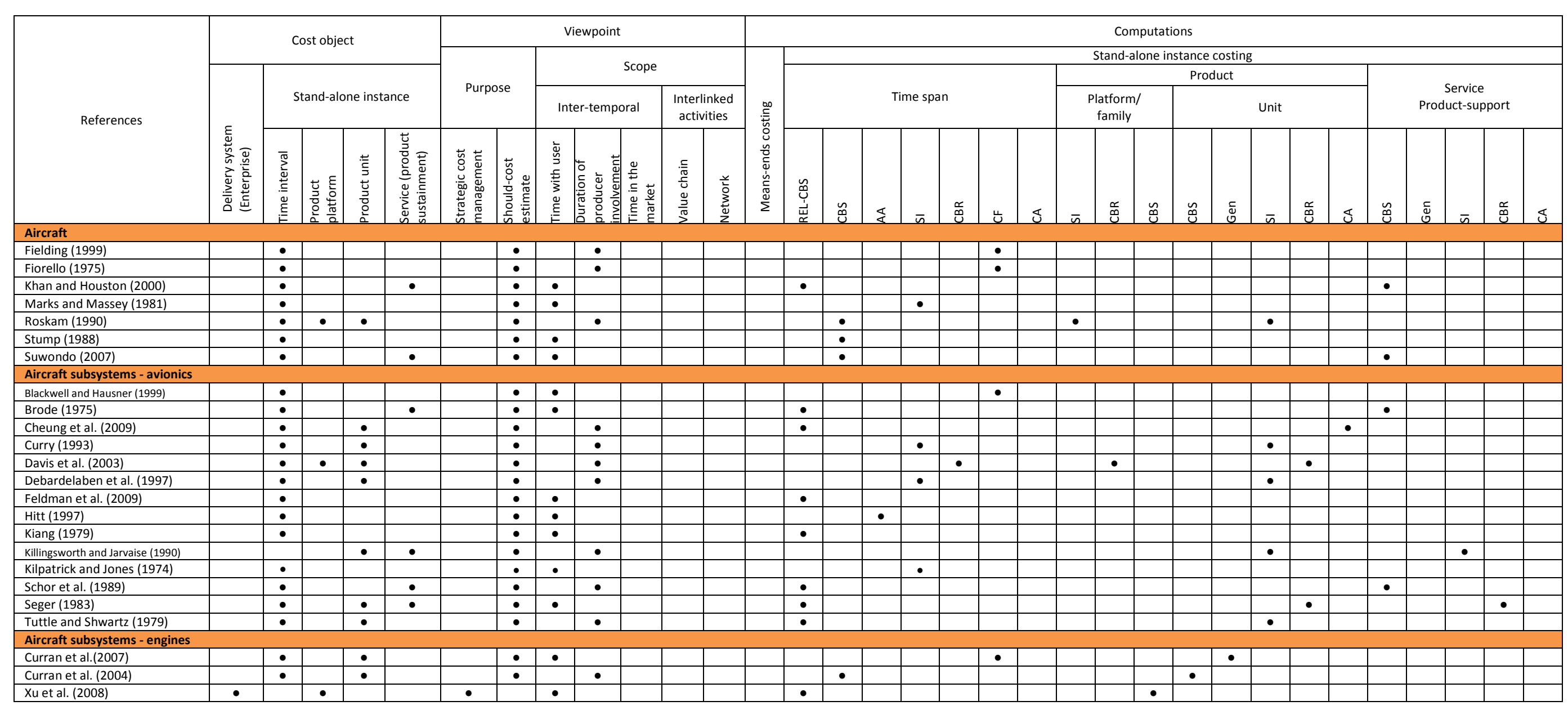


Table 4 (continued) - Quantitative research in TLC - "product and support" business model.

\begin{tabular}{|c|c|c|c|c|c|c|c|c|c|c|c|c|c|}
\hline \multirow{4}{*}{ References } & \multicolumn{8}{|c|}{ Non-monetary metrics } & \multicolumn{5}{|c|}{ Uncertainty } \\
\hline & \multicolumn{5}{|c|}{ Primary } & \multicolumn{3}{|c|}{ Derived } & \multirow{3}{*}{ 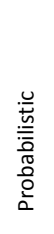 } & \multirow{3}{*}{ 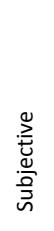 } & \multicolumn{3}{|c|}{ Random event generation } \\
\hline & \multirow{2}{*}{ 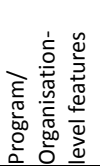 } & \multirow{2}{*}{ 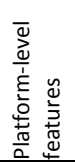 } & \multicolumn{2}{|c|}{ Unit-level metrics } & \multirow{2}{*}{ 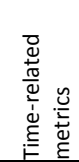 } & \multirow{2}{*}{ 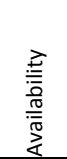 } & \multirow{2}{*}{ 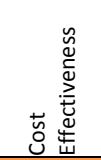 } & \multirow[b]{2}{*}{$\begin{array}{l}\overline{\grave{v}} \\
\stackrel{ \pm}{ \pm}\end{array}$} & & & \multirow[b]{2}{*}{ 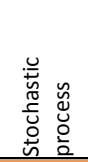 } & \multirow[b]{2}{*}{ 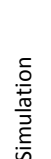 } & \multirow{2}{*}{ 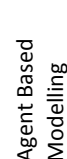 } \\
\hline & & & Product & Service & & & & & & & & & \\
\hline \multicolumn{14}{|l|}{ Aircraft } \\
\hline Fielding (1999) & & $\bullet$ & & & $\bullet$ & & & & & & & & \\
\hline Fiorello (1975) & & & & & $\bullet$ & & & & & & & & \\
\hline Khan and Houston (2000) & & & & & $\bullet$ & & & & & & & & \\
\hline Marks and Massey (1981) & & $\bullet$ & & $\bullet$ & $\bullet$ & & & & & & & & \\
\hline Roskam (1990) & & $\bullet$ & & & $\bullet$ & & & & & & & & \\
\hline Stump (1988) & & & & & $\bullet$ & & & & $\bullet$ & & $\bullet$ & & \\
\hline Suwondo (2007) & & $\bullet$ & & $\bullet$ & $\bullet$ & & $\bullet$ & & & & & & \\
\hline \multicolumn{14}{|l|}{ Aircraft subsystems - avionics } \\
\hline Blackwell and Hausner (1999) & & . & & & $\bullet$ & & & & & & & & \\
\hline Brode (1975) & & $\bullet$ & & $\bullet$ & $\bullet$ & & & & & & & & \\
\hline Cheung et al. (2009) & & & $\bullet$ & & & & & & & & & & \\
\hline Curry (1993) & & $\bullet$ & & & & & & & & & & & \\
\hline Davis et al. (2003) & & $\bullet$ & & & & & & & & & & & \\
\hline Debardelaben et al. (1997) & & $\bullet$ & & & & & & & & & & & \\
\hline Feldman et al. (2009) & & $\bullet$ & & & $\bullet$ & $\bullet$ & & & $\bullet$ & & & $\bullet$ & \\
\hline Hitt (1997) & & & & & $\bullet$ & & & & & & & & \\
\hline Kiang (1979) & & $\bullet$ & & & $\bullet$ & $\bullet$ & & & $\bullet$ & & $\bullet$ & & \\
\hline Killingsworth and Jarvaise (1990) & & $\bullet$ & & & & & & & & & & & \\
\hline Kilpatrick and Jones (1974) & & $\bullet$ & & & $\bullet$ & & & & & & & & \\
\hline Schor et al. (1989) & & $\bullet$ & & $\bullet$ & $\bullet$ & $\bullet$ & & & $\bullet$ & & $\bullet$ & & \\
\hline Seger (1983) & & $\bullet$ & & & $\bullet$ & & & & & & & & \\
\hline Tuttle and Shwartz (1979) & & $\bullet$ & & & $\bullet$ & & & & & & & & \\
\hline \multicolumn{14}{|l|}{ Aircraft subsystems - engines } \\
\hline Curran et al.(2007) & & $\bullet$ & $\bullet$ & & $\bullet$ & & & & & & & & \\
\hline Curran et al. (2004) & & $\bullet$ & $\bullet$ & & $\bullet$ & & & & & & & & \\
\hline Xu et al. (2008) & & $\bullet$ & & & $\bullet$ & & & & & & & & \\
\hline
\end{tabular}


Table A.5 Quantitative research in TLC - "product and support" business model - non aerospace applications. (Abbreviations: see Table 4).

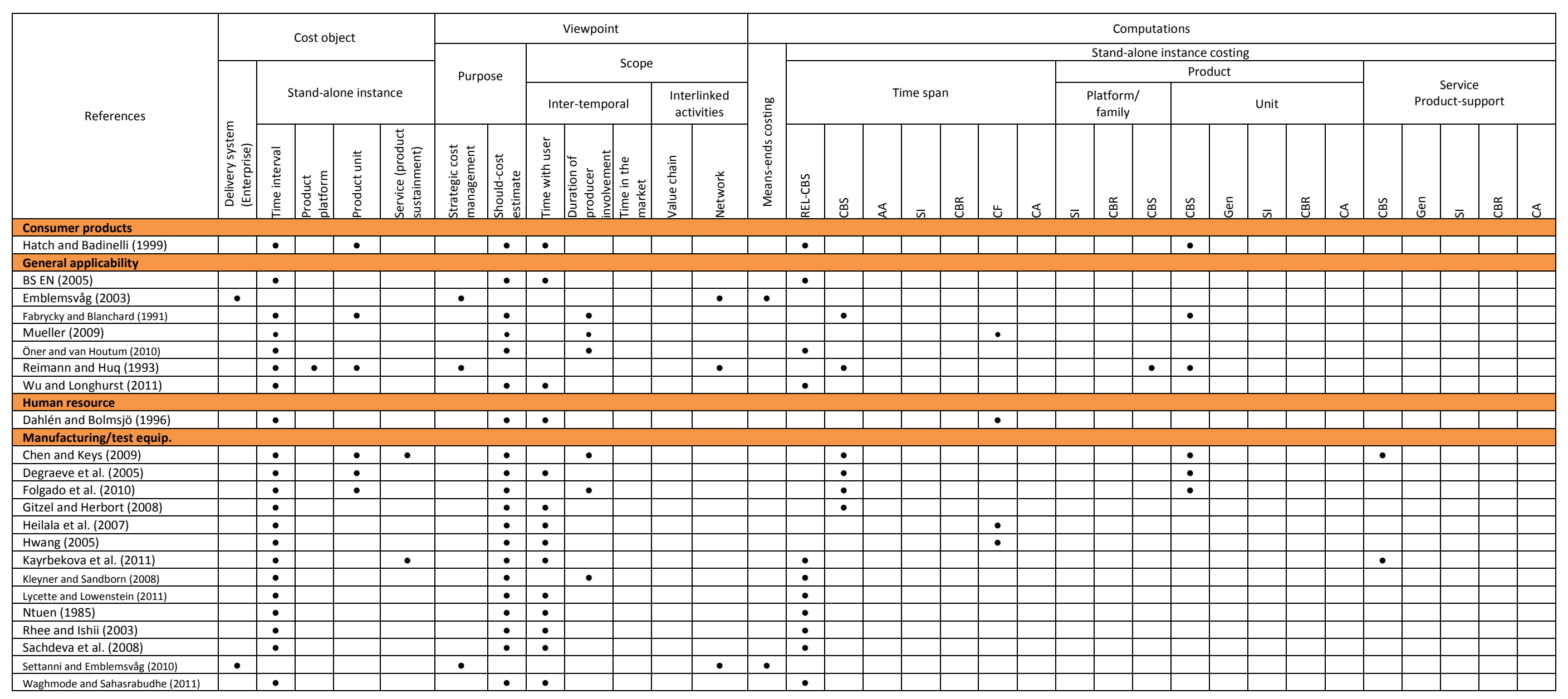


Table A.5 (continued) - Quantitative research in TLC - "product and support" business model - non aerospace applications.

\begin{tabular}{|c|c|c|c|c|c|c|c|c|c|c|c|c|c|}
\hline \multirow{4}{*}{ References } & \multicolumn{8}{|c|}{ Non-monetary metrics } & \multicolumn{5}{|c|}{ Uncertainty } \\
\hline & \multicolumn{5}{|c|}{ Primary } & \multicolumn{3}{|c|}{ Derived } & \multirow{3}{*}{ 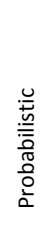 } & \multirow{3}{*}{ 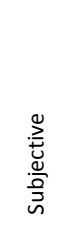 } & \multicolumn{3}{|c|}{ Random event generation } \\
\hline & \multirow{2}{*}{ 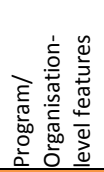 } & \multirow{2}{*}{ 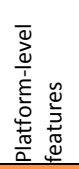 } & \multicolumn{2}{|c|}{ Unit-level metrics } & \multirow{2}{*}{ 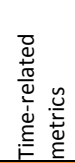 } & \multirow{2}{*}{ 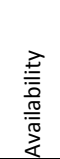 } & \multirow{2}{*}{ 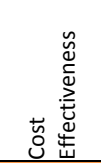 } & \multirow[b]{2}{*}{$\begin{array}{l}\bar{q} \\
\overline{ \pm}\end{array}$} & & & \multirow[b]{2}{*}{ 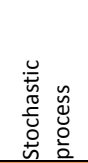 } & \multirow{2}{*}{ 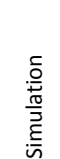 } & \multirow{2}{*}{ 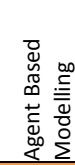 } \\
\hline & & & Product & Service & & & & & & & & & \\
\hline \multicolumn{14}{|l|}{ Consumer products } \\
\hline Hatch and Badinelli (1999) & & $\bullet$ & $\bullet$ & & $\bullet$ & $\bullet$ & & & $\bullet$ & & & & \\
\hline \multicolumn{14}{|l|}{ General applicability } \\
\hline BS EN (2005) & & $\bullet$ & $\bullet$ & $\bullet$ & $\bullet$ & $\bullet$ & & & $\bullet$ & & & & \\
\hline Emblemsvåg (2003) & & $\bullet$ & $\bullet$ & & $\bullet$ & & & & $\bullet$ & & & $\bullet$ & \\
\hline Fabrycky and Blanchard (1991) & & $\bullet$ & $\bullet$ & & $\bullet$ & & & & & & & & \\
\hline Mueller (2009) & & & & & $\bullet$ & & & & & & & & \\
\hline Öner and van Houtum (2010) & & $\bullet$ & & & $\bullet$ & & & & $\bullet$ & & $\bullet$ & & \\
\hline Reimann and Huq (1993) & & & $\bullet$ & & & & & & $\bullet$ & & & $\bullet$ & \\
\hline Wu and Longhurst (2011) & & $\bullet$ & & & $\bullet$ & & & & $\bullet$ & & & & \\
\hline \multicolumn{14}{|l|}{ Human resource } \\
\hline \multirow{2}{*}{\multicolumn{14}{|c|}{$\begin{array}{l}\text { Dahlén and Bolmsjö (1996) } \\
\text { Manufacturing/test equip. }\end{array}$}} \\
\hline & & & & & & & & & & & & & \\
\hline Chen and Keys (2009) & & $\bullet$ & $\bullet$ & $\bullet$ & $\bullet$ & & & & & & & & \\
\hline Degraeve et al. (2005) & $\bullet$ & - & & & & & & & & & & & \\
\hline Folgado et al. (2010) & & $\bullet$ & $\bullet$ & & $\bullet$ & & & & & & & & \\
\hline Gitzel and Herbort (2008) & & $\bullet$ & & & $\bullet$ & & & & & & & & \\
\hline Heilala et al. (2007) & & $\bullet$ & & & $\bullet$ & & & $\bullet$ & & & & & \\
\hline Hwang (2005) & & $\bullet$ & & & $\bullet$ & & & $\bullet$ & $\bullet$ & & & $\bullet$ & \\
\hline Kayrbekova et al. (2011) & & & & $\bullet$ & & & & & & & & & \\
\hline Kleyner and Sandborn (2008) & & $\bullet$ & & & $\bullet$ & & & & $\bullet$ & & & $\bullet$ & \\
\hline Lycette and Lowenstein (2011) & & $\bullet$ & & & $\bullet$ & & & & & & & & \\
\hline Ntuen (1985) & & - & & & $\bullet$ & $\bullet$ & & & $\bullet$ & & & - & \\
\hline Rhee and Ishii (2003) & & $\bullet$ & & $\bullet$ & $\bullet$ & $\bullet$ & & & $\bullet$ & & & $\bullet$ & \\
\hline Sachdeva et al. (2008) & & $\bullet$ & & & $\bullet$ & $\bullet$ & & & $\bullet$ & & & $\bullet$ & \\
\hline Settanni and Emblemsvåg (2010) & & & & & & & & $\bullet$ & $\bullet$ & & & $\bullet$ & \\
\hline Waghmode and Sahasrabudhe (2011) & & $\bullet$ & $\bullet$ & $\bullet$ & $\bullet$ & & & & $\bullet$ & & $\bullet$ & & \\
\hline
\end{tabular}


Table A.6 Quantitative research in TLC - "product and support" business model - military equipment and other applications. (Abbreviations: see Table 4).

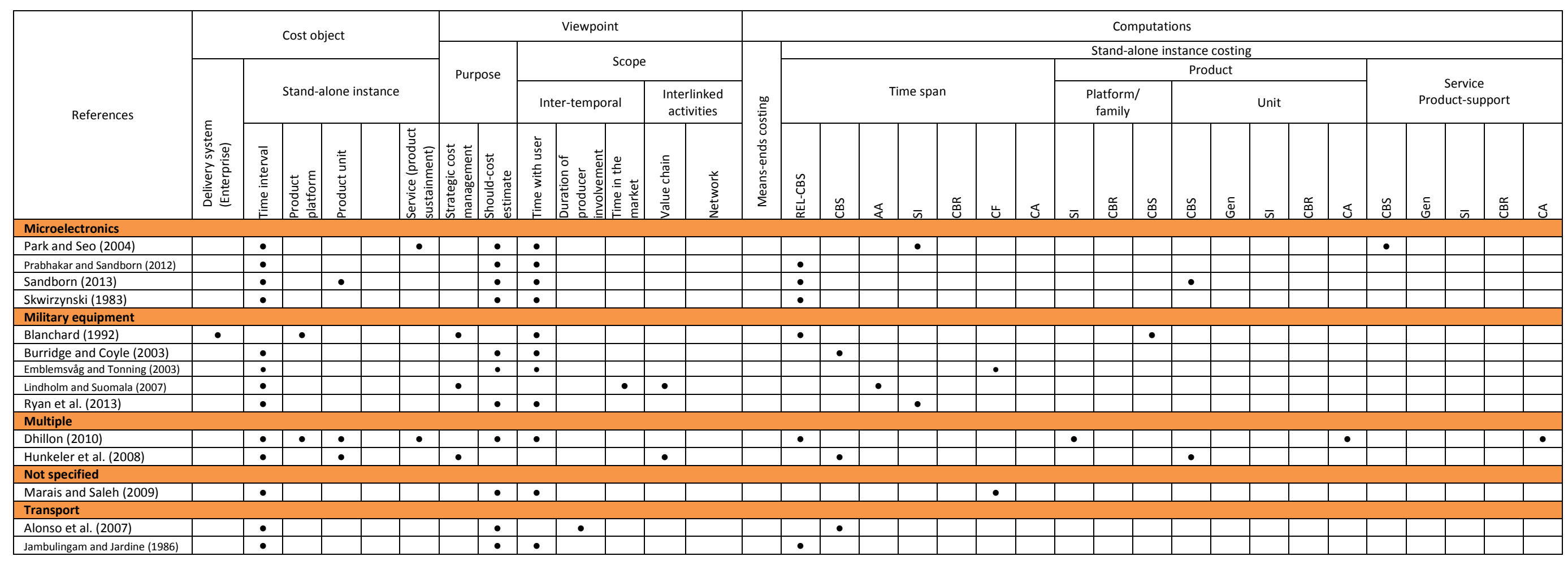


Table A.6 (continued) - Quantitative research in TLC - "product and support" business model - military equipment and other applications.

\begin{tabular}{|c|c|c|c|c|c|c|c|c|c|c|c|c|c|}
\hline \multirow{4}{*}{ References } & \multicolumn{8}{|c|}{ Non-monetary metrics } & \multicolumn{5}{|c|}{ Uncertainty } \\
\hline & \multicolumn{5}{|c|}{ Primary } & \multicolumn{3}{|c|}{ Derived } & \multirow{3}{*}{ 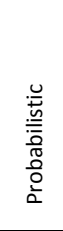 } & \multirow{3}{*}{ 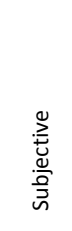 } & \multicolumn{3}{|c|}{ Random event generation } \\
\hline & \multirow{2}{*}{ 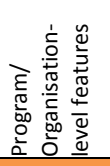 } & \multirow{2}{*}{ 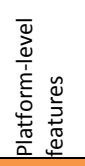 } & \multicolumn{2}{|c|}{ Unit-level metrics } & \multirow{2}{*}{ 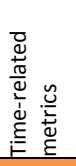 } & \multirow[b]{2}{*}{ 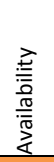 } & \multirow{2}{*}{ 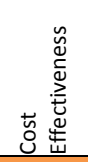 } & \multirow[b]{2}{*}{ 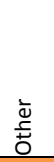 } & & & \multirow[b]{2}{*}{ 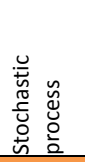 } & \multirow[b]{2}{*}{ 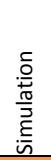 } & \multirow{2}{*}{ 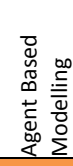 } \\
\hline & & & Product & Service & & & & & & & & & \\
\hline \multicolumn{14}{|l|}{ Microelectronics } \\
\hline Park and Seo (2004) & & $\cdot$ & & & $\bullet$ & & & & & & & & \\
\hline Prabhakar and Sandborn (2012) & & $\bullet$ & $\bullet$ & & - & & & & & & & & \\
\hline Sandborn (2013) & & $\bullet$ & $\bullet$ & $\bullet$ & $\bullet$ & $\bullet$ & & & $\cdot$ & & & $\bullet$ & \\
\hline Skwirzynski (1983) & & $\bullet$ & & & $\cdot$ & $\cdot$ & $\cdot$ & & $\cdot$ & & & $\cdot$ & \\
\hline \multicolumn{14}{|l|}{ Military equipment } \\
\hline Blanchard (1992) & & $\bullet$ & $\cdot$ & & - & & $\cdot$ & & $\cdot$ & & & & \\
\hline Burridge and Coyle (2003) & & & & & $\bullet$ & & & & & & & & \\
\hline Emblemsvåg and Tonning (2003) & & & & & & & & - & & - & & - & \\
\hline Lindholm and Suomala (2007) & & & & & - & & & & - & & & $\bullet$ & \\
\hline Ryan et al. (2013) & - & & & & $\cdot$ & & & & & & & & \\
\hline \multicolumn{14}{|l|}{ Multiple } \\
\hline Dhillon (2010) & & $\cdot$ & $\cdot$ & $\cdot$ & $\cdot$ & $\cdot$ & & & $\bullet$ & & & & \\
\hline Hunkeler et al. (2008) & & & $\bullet$ & & $\cdot$ & & & $\cdot$ & & & & & \\
\hline \multicolumn{14}{|l|}{ Not specified } \\
\hline Marais and Saleh (2009) & & & & & $\bullet$ & & & & $\cdot$ & & $\cdot$ & & \\
\hline \multicolumn{14}{|l|}{ Transport } \\
\hline Alonso et al. (2007) & & - & - & & - & & & $\cdot$ & & & & & \\
\hline Jambulingam and Jardine (1986) & & - & & & - & & & & - & & & & \\
\hline
\end{tabular}

